\title{
Uncovering multilayered vulnerability and resilience in rural villages in the Pacific: a case study of Ono Island, Fiji
}

\author{
Daniela Medina Hidalgo $^{1,2}$, Patrick D. Nunn ${ }^{1}$ and Harriot Beazley ${ }^{1}$
}

\begin{abstract}
Peripheral communities across the Pacific are progressively being recognized as priority areas for the implementation of climate change adaptation strategies. A key step in planning and implementing effective adaptation actions is to identify what elements are driving vulnerability and resilience. Building on existing vulnerability and resilience conceptual models, we developed and applied a conceptual framework to identify drivers of vulnerability and resilience in social-ecological systems. By unifying the two concepts of vulnerability and resilience into a single framework, it is possible to better capture drivers of coping, adaptive and transformative capacities, and how they relate to specific climate hazards. The aim of the framework is to provide the conceptual basis from which the two concepts can be applied in conjunction, rather than prescribing specific indicators. The proposed framework was applied using a participatory action research approach to identify drivers of resilience and vulnerability in three coastal villages on a peripheral rural island in Fiji. Results from the framework's application show that these communities are currently contextualized within multiple layers of vulnerability and resilience, driven by: dependency on external support to implement activities, lack of knowledge about novel management actions for dealing with rapid environmental change, high levels of agency, increased access to support and services, high levels of awareness about climate change impacts, disposition to implement change and learn, and capacity to mobilize community resources and support. The development and application of the framework highlights aspects of vulnerability and resilience that have been overlooked or undervalued in the past when designing and implementing strategies for climate change adaptation in small island developing states (SIDS). The proposed framework has the potential to help overcome existing barriers in designing and implementing successful adaptation strategies, optimizing their effectiveness and sustainability in ways that are aligned with the unique situations of many SIDS.
\end{abstract}

Key Words: adaptation; climate change; Fiji; resilience; sea-level rise; vulnerability

\section{INTRODUCTION}

Climate change is expected to amplify existing pressures on human and environmental systems, hindering the capacity of countries to achieve sustainable development goals (Kelman 2017). Because international attention continues to focus on providing support to vulnerable countries such as small island developing states (SIDS), there is increasing need to improve climate change adaptation planning and implementation (Klöck and Nunn 2019, Nunn and McNamara 2019). The complexity of human and environmental systems, coupled with uncertainties in the direction and magnitude of climate change impacts, makes climate change adaptation planning a challenging task (Wise et al. 2014). In remote and rural communities, livelihoods are often directly linked to and influenced by natural resources and ecosystems, which rely greatly on endogenous capacities for management and governance (Nunn and Kumar 2018).

Most management decisions made in complex systems result in feedbacks and trade-offs among environmental, social, and economic aspects of the systems (Papadimitriou et al. 2019). Local communities in developing-country contexts are being forced to increase their capacities to manage systems in ways that allow them to achieve livelihood and development goals under changing environmental baselines (Medina Hidalgo et al. 2020). To respond to these challenges, it is critical to empower communities with tools and knowledge to be able to apply a systems-thinking approach that can facilitate decision-making (Robinson 2019). Here, we explore the concepts of resilience and vulnerability as useful frames to reorganize traditional environmental knowledge and enhance local capacities so they can be included effectively in the development and implementation of climate change adaptation strategies.

\section{Vulnerability and resilience as key concepts for climate adaptation planning}

A common departure point in the design of adaptation strategies is to define and understand a system's vulnerability (Johnson et al. 2016). The main objective of vulnerability analysis is to identify how and to what degree potential climate-related risks can affect a system (Preston et al. 2011). The way of understanding and defining vulnerability influences how decision makers at all levels respond to climate change, and which actions, communities, sectors, and stakeholders should be prioritized (Preston et al. 2011). The concept of vulnerability is multifactorial because it includes interactions with other elements such as exposure, sensitivity, and adaptive capacity (IPCC 2007, 2014a). The approach to understanding vulnerability in the latest (fifth) Intergovernmental Panel on Climate Change (IPCC) assessment report (AR5) involved the introduction of a risk factor to this conceptual model (IPCC 2014a). In the AR5 framework, the concepts of sensitivity and adaptive capacity are integrated into the vulnerability concept. Hence a system's vulnerability is determined by how susceptible a system is to particular climate hazards, as well as the capacity of the system to adapt and cope with the impacts and to implement change to avoid potential loss and damage (IPCC 2014a).

In a review of the different approaches for understanding and defining vulnerability, Joakim et al. (2015) propose that vulnerability can be organized into four categories: (1) a 
threshold, (2) exposure to hazards, (3) a preexisting condition, and (4) an outcome. In the climate change adaptation literature, the two most commonly used approaches are vulnerability as a preexisting condition and vulnerability as an outcome (O'Brien et al. 2007, IPCC 2014a). The first approach refers to existing socioeconomic conditions that reduce a system's capacity to react to a hazard and make the system more susceptible to impacts. The second approach is defined as the residual adverse consequences that persist after adaptation has taken place.

The concept of resilience was introduced to the environmental sciences in 1973 to describe the capacity of an ecosystem to persist in its original functioning structure despite perturbations (Holling 1973). The concept of resilience has evolved over time and is used in different disciplines. A recent application of this concept has been in the study of social-ecological systems (SESs) and their responses to stressors such as climate change (Folke et al. 2010, Tanner et al. 2015). Since the IPCC's fourth assessment report, the concept of resilience has become acknowledged as key to understanding system responses to climate change (IPCC 2007). The concept of resilience was introduced to the field of climate change adaptation in an attempt to shift the focus from a system's capacity to deal with specific climate risks toward the assessment of a system's multiple responses to change, self-organization, and transformation capacity (Adger et al. 2011). A review of the topic identifies three typologies of resilience: static, adaptive, and transformative (Davidson et al. 2016). The conceptualization we use is aligned with the transformative resilience type, prominent in studies focusing on SESs.

When studying SESs, resilience thinking approaches have been used to determine the drivers of a system and its capacity to absorb shocks and stressors while maintaining structure and functionality (Walker et al. 2004). These characteristics define how a system can cope, self-organize, learn, and adapt in scenarios of change and uncertainty to attain desired outcomes and goals (Walker et al. 2006). Strategies that increase a system's resilience can be implemented either beforehand (proactive adaptation and transformational planning) or after the fact (response, reorganization, and recovery; Shah et al. 2017). The concept of resilience has evolved into one that seeks to involve the understanding of complex system dynamics and how SESs can thrive within scenarios of uncertainty and change (Folke 2016). Three aspects of resilience are typically analysed in SESs:

1. Buffer or coping capacity: The capacity of a system to recover from incremental and abrupt change by absorbing shocks and finding a new stability domain that includes the loss of some functions, structures, or identities (Speranza 2013).

2. Adaptability: The capacity to allow a system to shift between basins of attraction and purposefully transition into new stability domains. SESs can move from one basin of attraction to another by leading the system across a threshold to a new state in which system functions and integrity are maintained (Walker et al. 2004, Darnhofer et al. 2010).

3. Transformability: The capacity to bounce back better from change, reconfiguring the system and being able to identify new opportunities and development pathways (Bousquet et al. 2016, Folke 2016).
These three aspects of resilience are manifested across spatial and temporal scales, depending on the magnitude and nature of the changes and shocks that systems experience (Folke et al. 2016). Determining what can or should be considered a "desirable state" in a system and at what point a system must cope, adapt, or transform is highly context specific (Clare et al. 2017). Defining what is a desirable state for an SES cannot be objectively and universally described because it involves social and cultural value judgements about what is considered important to preserve (Shah et al. 2017).

Our study builds on existing vulnerability and resilience conceptual applications, including vulnerability assessments in SESs, livelihood resilience assessments, and mixed vulnerability and resilience frameworks (Maru et al. 2014, Joakim et al. 2015, Quandt 2018, Thiault et al. 2018). We focus on the development and application of a conceptual framework that could be adopted within the context of peripheral communities in SIDS. We applied the proposed conceptual model through a participatory process in rural villages on an outer island in the Fiji archipelago to identify drivers of vulnerability and resilience to climate hazards.

\section{CONCEPTUAL FRAMEWORK: A MULTILAYERED VULNERABILITY AND RESILIENCE CONCEPTUAL MODEL FOR SOCIAL-ECOLOGICAL SYSTEMS}

The vulnerability of remote subsistence-based communities in SIDS is often attributed to their geographic and socioeconomic characteristics (Barnett and Waters 2016). Nevertheless, these communities often exhibit attributes associated with resilience (Warrick et al. 2017). We define the coexistence of attributes of vulnerability and resilience across time and space as multilayered vulnerability and resilience. The framework development resulted from a critical review of the literature on the advantages and shortcomings of vulnerability and resilience frameworks. As a common feature of this type of review, we used purposive, rather than comprehensive, sampling of articles (Paré et al. 2015).

The review targeted scientific articles published in peer-reviewed journals since 2010. The search was conducted using the SCOPUS and Web of Science databases and the search terms: "vulnerability", "resilience", "community", "assess*", and "climate change". Focus was placed on the use and evolution of these concepts in the field of climate change adaptation research and their operationalization in support of climate adaptation planning in SESs. Emphasis was given to ways in which the existing conceptual frameworks might be adapted to support climate change adaptation decision-making in local contexts. Articles were organized in both databases based on relevance, and the search was stopped when there were no additional relevant articles matching the research questions on the results page of the search query. In total, 95 articles were screened and coded to identify recommendations and pitfalls to avoid when applying both concepts (vulnerability and resilience).

Vulnerability and resilience indices and indicators have become key tools in operationalizing the concepts (Kerner and Thomas 2014, Cogswell et al. 2018), motivating researchers and practitioners to develop a variety of methods that aim to identify drivers that exacerbate or reduce vulnerability and resilience (Thiault et al. 2018). Differences among indices are often outcomes of the different ways in which researchers define the concepts and determine the relationships among their key components (Adger et al. 2004, Birkmann et al. 2015). One of the 
main criticisms of vulnerability and resilience indices is that they simplify complex concepts by desegregating them into measurable indicators (Hinkel 2011). An additional limitation identified in existing indices is the use of prescriptive and normative indicators that are selected based on "expert" opinion or indicators that have been used and applied in the literature in diverse contexts as proxy measures of vulnerability and resilience (Wilson and Wilson 2019). For example, indicators such as household income levels or per-capita income are not necessarily strong indicators of vulnerability and resilience in contexts that operate in a subsistence-based economy that is largely reliant on nonmonetary services and exchange.

Defining the boundaries of a system is key to identifying drivers of vulnerability and resilience and determining the scope of analysis (Thiault et al. 2018). In cases where populations have strong connections with the environment for income and livelihoods, the social and ecological determinants of vulnerability are closely linked (Marshall et al. 2013, IPCC 2014b, Metcalf et al. 2015). Analyzing social or ecological systems separately ignores the complexity, feedback mechanisms, and interactions among subsystems (Bodin 2017, Berrouet et al. 2018). This aspect is often overlooked when characterizing vulnerability, leading indices to be based primarily on quantitative socioeconomic indicators that can be easily aggregated and tracked over time (Berrouet et al. 2018). In an attempt to capture the interactions and feedback loops between social and natural systems, research on SESs has gained increased importance in the literature since the 2000s (Bousquet et al. 2016). Here, we adhere to a comprehensive definition of SES, which defines ecological systems as ecosystems and natural resources linked to and affected by social systems (Anderies et al. 2004). Social systems can be understood as human communities and the way in which knowledge, culture, economy, technology, and governance are used to manage and distribute resources (Levin et al. 2013, IniestaArandia et al. 2014).

One of the most commonly studied relationships in SESs is the capacity of ecological systems to provide ecosystem services (Berrouet et al. 2018, Pearson et al. 2019). Understanding this relationship allows the vulnerabilities of ecological and social systems to be quantified through the assessment of losses and gains in ecosystem services (Biggs et al. 2015). Numerous analytical frameworks have been developed to assess socialecological vulnerabilities at different spatial scales and in different contexts (Hay and Mimura 2013, Marshall et al. 2014, Birkmann et al. 2015, Berrouet et al. 2018).

The present study is based on a new conceptual model that links social and ecological vulnerability through the use and delivery of ecosystem services (Fig. 1). The IPCC AR5 conceptual model of risk links the vulnerabilities of social and ecological systems. The magnitude and occurrence likelihood of climate-related hazards generated by climate variability and likely future climate change determines system exposure to such hazards. Both ecological and social systems are exposed to hazards, and their vulnerability is defined based on their capacity to adapt and how sensitive they are to potential impacts. Certain hazards such as extreme events can directly affect social subsystems (e.g., deaths occurring during a tropical cyclone). Nevertheless, most impacts deriving from slow-onset climate hazards create effect chains linked by interactions between the subsystems.
Fig. 1. Vulnerability of social-ecological systems, expressed by delivery and use of ecosystem services between social and ecological subsystems. Sources: Marshall et al. (2013), IPCC (2014), Berrouet et al. (2018), Thiault et al. (2018).

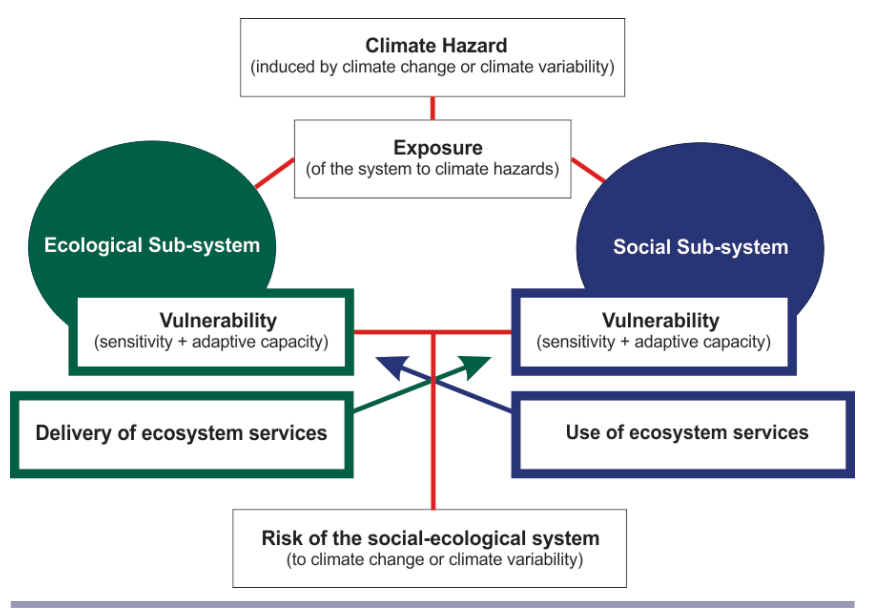

Applying the resilience concept in SES and environmental change research, some researchers noted that stability domains might not necessarily be desirable states for a system (Folke 2006, 2016, Tanner et al. 2015). For example, an SES can be trapped in an undesirable state such as poverty or marginality while still being able to deal with and respond to change (Tanner et al. 2015). This situation highlights the need to frame resilience and vulnerability as dynamic attributes of a system that can be increased or reduced to lead a system to a desirable state. Such desirable states cannot be universally defined and require the inclusion of subjective perspectives and values that stakeholders pursue in a system (Clare et al. 2017). Additionally, management actions or interventions aimed at building resilience or reducing vulnerability should be framed as dynamic processes rather than outcomes (Lei et al. 2014).

One of the most consistent points identified in the literature is the lack of a single resilience or vulnerability tool applicable to all contexts (Dixon and Stringer 2015, Douxchamps et al. 2017). Consequently, the aim of the multilayered vulnerability and resilience model for SESs presented here is to provide a framework in which the concepts of vulnerability and resilience can be applied together instead of an aggregated index-based tool with fixed indicators. Some authors have described the relationship between vulnerability and resilience as opposing concepts, in the sense that increasing a system's resilience would reduce its vulnerability and vice versa (Haimes 2012). Another way of understanding both concepts to view them as distinct, yet linked over time and space. In the conceptual model, we adhere to an understanding of both concepts as distinct and interconnected, as suggested by a number authors (Miller et al. 2010, Joakim et al. 2015). This approach recognizes that a system can simultaneously exhibit characteristics of vulnerability and resilience, which may each increase or diminish over time independently or in conjunction.

Levels of vulnerability and resilience are dynamic. They shift based on the magnitude of hazards, changes in governance or management, and the selection and implementation of different adaptation strategies. Adaptation strategies could be designed 
Fig. 2. Conceptual model of multilayered vulnerability and resilience in social-ecological systems, based on the Intergovernmental Panel on Climate Change fifth assessment report (IPCC 2014) risk model. Vulnerability and resilience are linked through the adaptive capacity attribute. Drivers of vulnerability and resilience can be modified to reduce risks or take advantage of new opportunities.

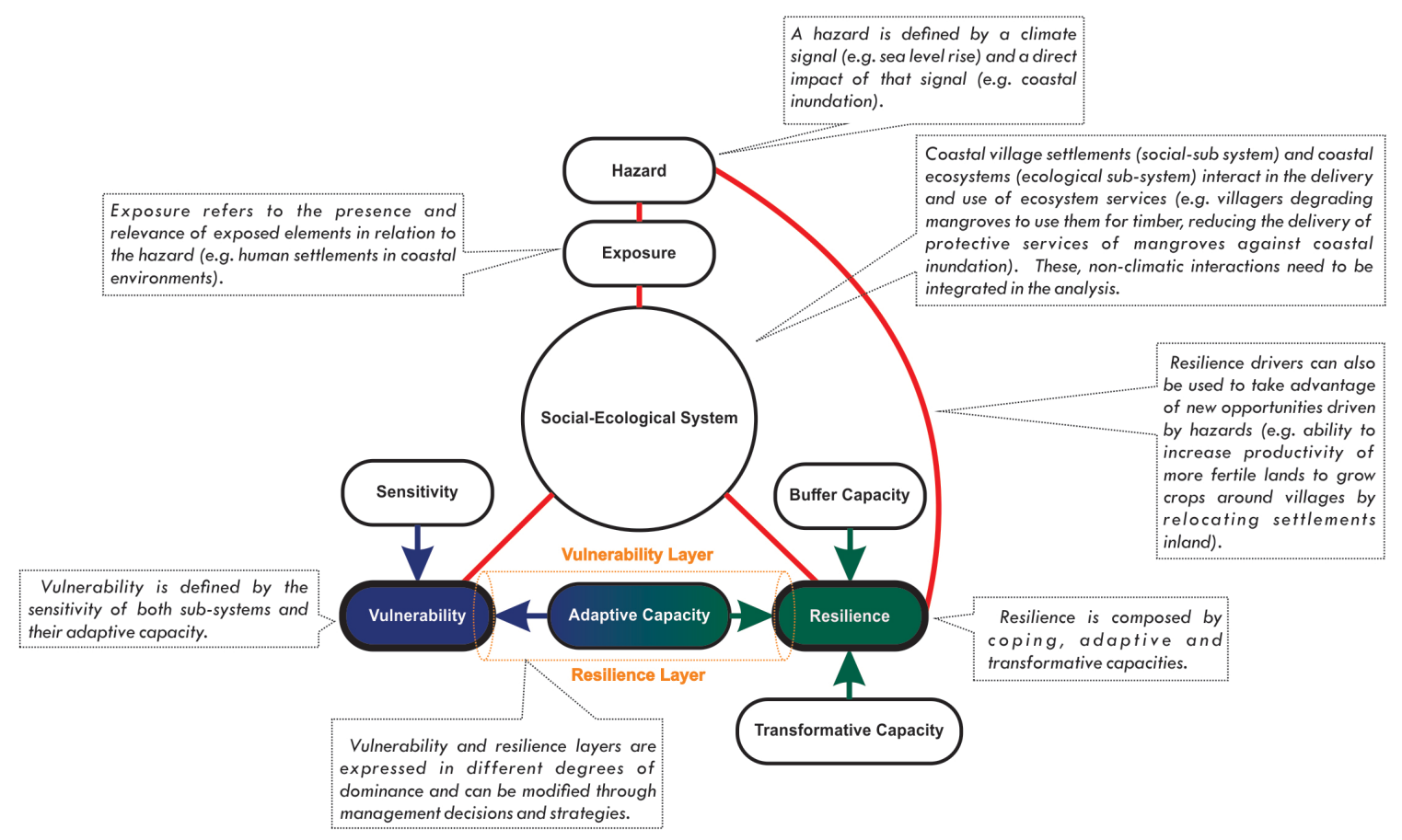

either to increase and use drivers of resilience and decrease or to manage drivers of vulnerability. By characterizing which elements drive vulnerability and resilience when exposed to specific hazards, it is possible to improve and better target the process of climate change adaptation planning (Begum et al. 2014). Although understanding vulnerability and resilience is not the only requisite for effective adaptation planning, it is a key aspect that allows decision-makers to understand how nonclimatic pressures and existing social-ecological conditions might increase risks and potential impacts under climate change (Joakim et al. 2015). Lack of understanding of a system's resilience and vulnerability can often lead to maladaptation or narrowly focused adaptation strategies that deal only with direct effects of climate hazards, missing opportunities for transformation (Adhikari and Taylor 2012). Understanding the drivers of vulnerability and resilience could facilitate the process of representing system dynamics when attempting to model systems responses using climate projections (Papadimitriou et al. 2019).

The proposed multilayered conceptual model (Fig. 2) builds and expands on the IPCC AR5 conceptualization of risk. The risk conceptualization used in AR5 contributes to the integration of the research disciplines of climate change adaptation and disaster risk reduction (Connelly et al. 2018) and has been highlighted as key to improving the effectiveness of responses to current and future climate risks (Begum et al. 2014). By applying the framework systematically, it is possible to identify how vulnerability and resilience attributes enhance or reduce risks to specific climate hazards. Elements of vulnerability or resilience to different hazards can be complementary or opposing. For that reason, when using the model, it is important to identify those relationships for every hazard studied.

In our framework, we suggest that the concepts of vulnerability and resilience should be applied as part of an assessment of risks linked to specific hazards and how they affect SESs. Additionally, defining the boundaries of a system and the scope of the analysis facilitates a better understanding of the system's configuration and its relationship to the shocks that are being analyzed (also referred to as "resilience of what to what?"; Carpenter et al. 2001). In other words, the two concepts are used to determine current and future risks by placing them within the probability of occurrence of climate events or trends that lead to impacts (hazards), and the presence of natural or socioeconomic assets in places that could be affected (exposure).

As identified in similar frameworks, vulnerability and resilience are linked through the adaptive capacity attribute in our model (Gallopín 2006, Maru et al. 2014). By integrating the concept of resilience into the AR5 risk assessment model, it is possible to expand the analysis beyond characterizing adaptive capacity to include coping and transformative capacities of a system. Through this approach, drivers of resilience can also be enhanced to take advantage of new opportunities generated by climate change, instead of only responding to hazards (Bousquet et al. 2016). An added value of integrating vulnerability and resilience is that possibilities for proactive transformation can also be explored (Folke et al. 2016). Adaptation strategies would normally seek to reduce exposure, sensitivity, and vulnerability, 
and to increase adaptive capacity, coping capacity, or transformative capacity, with the goal to reduce risk, allow the system to absorb shocks, or lead the system through transformation pathways (Lei et al. 2014). Each approach selected should be based on existing barriers and limits to adaptation, which are also linked to the desired outcomes and current or future states of a system. Risk can also be reduced by additional risk management measures outside of the climate adaptation domain, such as risk transfer mechanisms, to deal with climate-related loss and damage (Begum et al. 2014).

The aim of the model is to support decision-makers in identifying layers of vulnerability and resilience that can be managed within a system. We use the word "layers" to illustrate that the concepts are not absolute or static attributes of a system, meaning that they can be exhibited simultaneously and in differing degrees of dominance. When applying the model, it is important to identify which layer dominates in the current status of the system, and which element of the system is to be managed to change attributes in the desired direction. By characterizing the different elements of the model, it is possible to identify entry points for adaptation strategies and to identify potential trade-offs or synergies that can result from managing different elements of the system or from responding to multiple hazards.

Other authors have elaborated on the concepts of vulnerability and resilience and the benefits in linking them to advance climate adaptation planning (Gallopín 2006, Joakim et al. 2015). Our model coincides with some key conceptual underpinnings such as viewing resilience and vulnerability as distinct yet interconnected concepts and linking both concepts through the adaptive capacity attribute. However, there are several aspects lacking in earlier models that we seek to advance. For example, the framework developed by Cutter et al. (2008) is based on a set of indicators of resilience but stops short of using the conceptual framework as a way to empower communities to identify what drives resilience and vulnerability in their particular contexts and according to their own knowledge, values, and aspirations. This usage is an element that has been identified as essential in the context of climate change adaptation processes in SIDS (PiggottMcKellar et al. 2020). In addition, the model proposed by Cutter et al. (2008) does not include the need for an explicit definition of levels of exposure and sensitivity, which are key determinants of potential risks and impacts. Further, in the model suggested by Maru et al. (2014), analysis is based on how both concepts relate to a specific attribute of the system (remoteness), whereas we base our analysis on how the two concepts modify a system's response to, and interactions with, climate hazards. In addition, the Maru et al.'s (2014) model defines vulnerability as produced by the contextual conditions of a system, instead of viewing vulnerability as a modifier of risk, as proposed in the conceptualization of vulnerability proposed in the IPCC AR5.

The literature review conducted for the development of our model also identified several pitfalls to be avoided when attempting to operationalize the concepts of vulnerability and resilience. For our model to remain conceptually grounded, we provide a set of recommendations that should be considered (as a minimum requirement) when attempting to operationalize it.
1. Framing the analysis within tangible development outcomes and defining a clear purpose for the analysis.

2. Accounting for subjective perspectives of risk, thresholds, and desired outcomes.

3. Capturing system interrelationships and complexities.

4. Identifying multiple shocks and stressors.

5. Defining what is understood as desirable and undesirable states for a system.

6. Capturing interactions across time and scale.

7. Representing as accurately as possible the heterogeneity of systems.

Such an approach will ensure that the model will be conceptually accurate and that the way in which it is applied is consistent with the principles that the concepts are intended to represent. Focusing not only on the concepts but also on the processes used to characterize different model components is an additional element that adds value to existing models. Appendix 1 contains a detailed description of the seven recommendations and concrete examples of steps taken during data collection and analysis that facilitated the integration of the seven recommendations in the application presented here.

\section{METHODS}

For the applied component of the study, the conceptual model was used to identify drivers of resilience and vulnerability in three coastal iTaukei (Indigenous) villages on a peripheral island in Fiji, named Ono. Ono Island is part of the Kadavu Province and is inhabited by approximately 300 people (Fiji Bureau of Statistics 2018). The island is located $80 \mathrm{~km}$ south of Fiji's capital city Suva (Fig. 3). Data were collected from three coastal villages on Ono (Narikoso, Vabea, and Waisomo), which have 31, 14, and 11 households, respectively. The choice of Ono Island and the three (from six) villages was based on the following criteria: (1) the sites are representative of the challenges faced by communities in peripheral parts of the Fiji archipelago, (2) residents' livelihoods are directly (and largely) dependent on the use and management of natural resources, and (3) there was explicit interest from the community and village leaders to participate in the project. The research was conducted using a participatory action research approach (Loo 2014). Data collection included culturally appropriate methods such as talanoa, which means to hold a dialogue process in an inclusive, respectful, and transparent manner to discuss and find solutions to issues of importance to the community (Farrelly and Nabobo-Baba 2014).

Researchers followed Fijian protocols, including isevusevu (the presentation of yaqona, Piper methysticum, to gain entrance to a community) and itatau (proper departure from the village). Consent to participate in the study was discussed with the village headman and then individually with participants. Researchers lived in the villages during the period of data collection, allowing the establishment of trust relationships. Semistructured interviews and focus group discussions (talanoa) were conducted in English. Primary data were collected in June and July 2019. When group discussions were organized, participants were separated by gender to allow everyone to feel comfortable when expressing their views or opinions. 
Fig. 3. Map of Viti Levu, Kadavu, and Ono islands, Fiji.

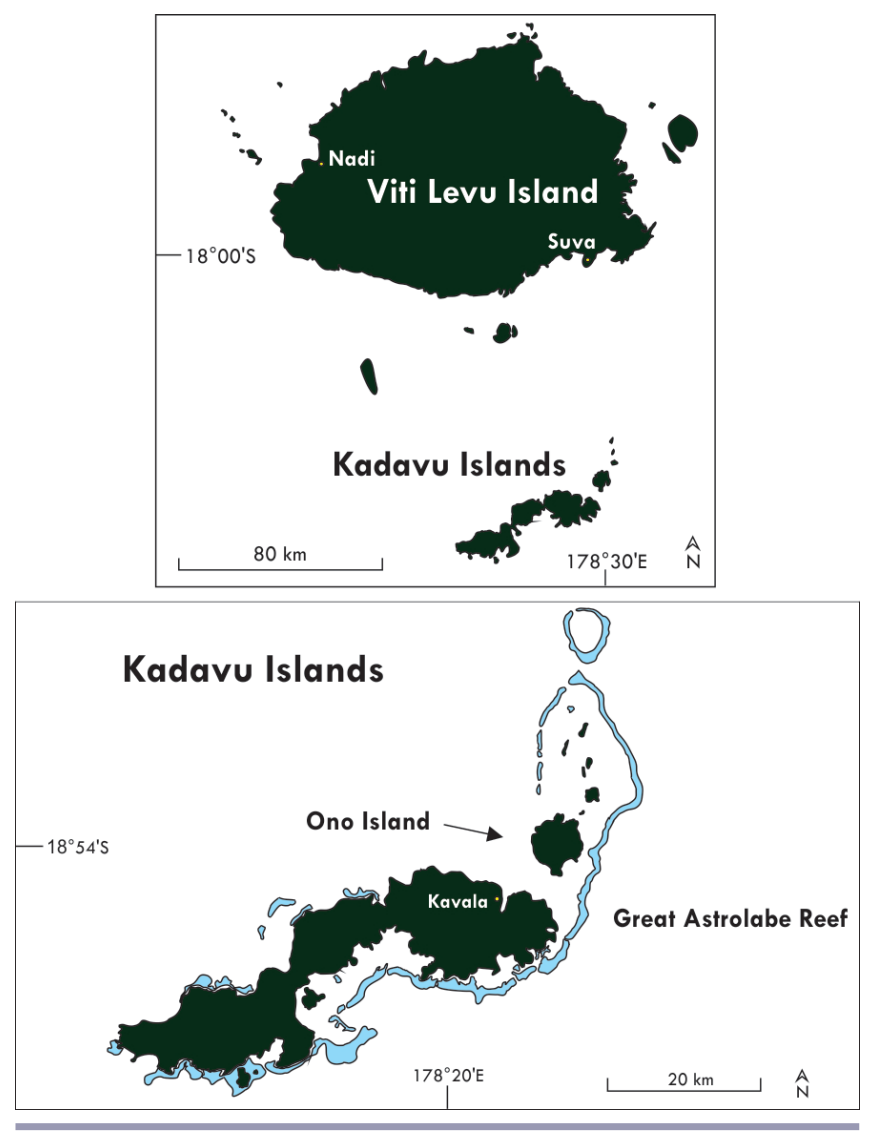

A total of 20 adult members ( 11 females and 9 males) participated. Participant recruitment was conducted using chain-referral sampling. The inclusion criterion to participate in the study was to have lived in the village for at least the past 20 years (i.e., since 1999). Interviews and group discussions were recorded and then manually transcribed. Text was manually coded using NVivo software. The coding process was done using a deductive approach, following the structure of the conceptual model components. A full description of the data collection protocol and the guiding questions that were used to characterize the different elements of the model is provided (Appendix 2).

\section{RESULTS}

The results obtained from applying our conceptual model are structured in three sections: experienced and projected climate hazards, interactions within the social-ecological systems, and multilayered vulnerability and resilience in the studied villages. During the first stage of engagement with research participants, two development objectives were prioritized: securing sources of livelihood and income, and sustaining households and current ways of living in the villages in the face of increasing climatedriven environmental changes. These two development objectives were used to frame the analysis. The purpose of the model's application was to identify drivers of vulnerability and resilience that could support future adaptation planning processes in the study area. The time frame for the analysis was limited to climate hazards and impacts experienced by the research participants between 1999 and 2019. Information about perceived changes was cross-referenced with documented climate changes in the region and extrapolated using available climate projections of key climate variables for the year 2050 .

\section{Experienced and projected climate hazards}

Experienced climate hazards on Ono Island

The interviewed Ono Island residents identified five climate hazards that have had significant effects on their livelihoods. Participants were able to describe changes in climate hazards in recent years and to recall details of the most severe extreme event in living memory, Category 4 Tropical Cyclone Meli in 1979, which caused massive environmental damage, loss of life, and loss of infrastructure (Table 1). The research participants also reported that persistent shoreline erosion and inundation had led to the construction of several seawalls and river-bank walls around the villages. At the time of research, Narikoso village was already undergoing relocation due to sea-level rise (Green 2016, Barnett and McMichael 2018). The decision to relocate was made after several failed attempts to prevent coastal inundation using seawalls.

Documented changes in climate variables and climate projections A widespread limitation for understanding climate change impacts in the Pacific relates to the geographic characteristics of small islands, which are difficult to model using current climate and biophysical models (Foley 2018). Compared to larger landmasses, most Pacific islands are small and fragmented, and the limitation in availability of historical climate data poses additional challenges for downscaling Global Circulation Models to a resolution that is relevant for the types of decision-making processes in planning adaptation strategies at the local level (Australian Bureau of Meteorology and CSIRO 2014). Furthermore, not all climate models are suitable for representing future climate in the region because they fail to simulate climate features such as the South Pacific Convergence Zone or drivers of climate variability such as El Niño-Southern Oscillation (ENSO), which are important influences on interannual climate in this region (Irving et al. 2011, Grose et al. 2014).

The Pacific Islands region experiences large interannual and decadal variations in sea level and rainfall, which affect coastal ecosystems (Nurse et al. 2014). Changes in the tidal and precipitation cycles are explained in part by ENSO events (Australian Bureau of Meteorology and CSIRO 2014). Sea level often drops to below-average levels during El Niño events and rises to above-average levels during La Niña events by as much as 20 to $30 \mathrm{~cm}$ (Becker et al. 2011). Besides affecting sea level, ENSO events in the Pacific affect sea surface temperature and precipitation variability (Becker et al. 2011). Some research suggests that in a warmer world, extreme El Niño events are projected to double from one every 20 years to one every 10 years (Cai et al. 2015). We summarized changes in observed trends of key climate variables and climate change projections at the country level (Table 2).

Interactions within the social-ecological system on Ono Island We next identify the SES in the studied villages as well as relationships between the use and delivery of ecosystem services. 
Table 1. Summary of observed changes in climate hazards and experienced impacts in Narikoso, Vabea, and Waisomo villages, Ono Island, Fiji, based on information from interviews with residents.

\begin{tabular}{|c|c|c|c|}
\hline Climate hazard & $\begin{array}{l}\text { Temporal } \\
\text { context }\end{array}$ & $\begin{array}{l}\text { Local changes in frequency or intensity over the past } 20 \\
\text { years }\end{array}$ & $\begin{array}{l}\text { Local aspects of livelihoods and ecosystems most affected by the } \\
\text { hazard }\end{array}$ \\
\hline $\begin{array}{l}\text { Higher } \\
\text { temperatures }\end{array}$ & Slow onset & $\begin{array}{l}\text { More days with higher temperatures; warmer days and } \\
\text { nights }\end{array}$ & $\begin{array}{l}\text { Loss of agricultural production; heat stress on animals and } \\
\text { humans, especially the elderly and newborns }\end{array}$ \\
\hline Drought & Slow onset & $\begin{array}{l}\text { Extension of dry season; more intense drought in certain } \\
\text { years }\end{array}$ & Loss of agricultural production; reduction of planting season \\
\hline $\begin{array}{l}\text { Tropical } \\
\text { cyclones }\end{array}$ & Transient & $\begin{array}{l}\text { Recollection of high intensity of cyclone Meli (1979); } \\
\text { since then, no other cyclone has directly affected the } \\
\text { island. No perceived changes in intensity or frequency of } \\
\text { cyclones }\end{array}$ & $\begin{array}{l}\text { Loss of human life; loss of housing infrastructure; complete loss of } \\
\text { agriculture production; loss of soil cover and soil fertility; } \\
\text { destruction of reef ecosystems; other tropical storms and cyclones } \\
\text { that have not affected the island directly have caused loss in } \\
\text { transport connectivity }\end{array}$ \\
\hline Sea-level rise & $\begin{array}{l}\text { Effectively } \\
\text { permanent }\end{array}$ & $\begin{array}{l}\text { Increase in rate of sea-level rise and intensity of storm } \\
\text { surges in the rainy season }\end{array}$ & $\begin{array}{l}\text { Saltwater intrusion; coastal flooding; beach erosion; housing } \\
\text { infrastructure damage }\end{array}$ \\
\hline $\begin{array}{l}\text { Extreme } \\
\text { rainfall events }\end{array}$ & $\begin{array}{l}\text { Sudden } \\
\text { onset }\end{array}$ & $\begin{array}{l}\text { Increase in intensity of rainfall events; increase of } \\
\text { frequency of high rainfall events in some years }\end{array}$ & $\begin{array}{l}\text { Contamination of drinking water sources; inundation of houses; } \\
\text { reduction in production of certain roots and tubers; higher } \\
\text { incidence of fungal and bacterial diseases in plants and humans; } \\
\text { loss of maritime transport connectivity; increased soil erosion and } \\
\text { runoff of sediments to the ocean }\end{array}$ \\
\hline
\end{tabular}

\section{Social subsystem}

People living on Ono Island maintain a semisubsistence economy (Medina Hidalgo et al. 2020). The most significant sources of cash income on the island are from small-scale agriculture, coastal fisheries, and tourism. The commercialization of yaqona or kava (Piper methysticum) is currently the most important source of agricultural income and a significant source of revenue for the broader Kadavu province (Sofer 2007). Ono islanders are connected to the main island of Viti Levu by a ferry that transports passengers and goods from nearby Kavala to and from Suva once a week. Electricity is supplied to the villages of Ono by diesel generators and solar panels.

In recent years, these villages have experienced changes to traditional livelihoods attributable to an increase in cashflow as well as improved access to electricity, phone services, and maritime transportation, which have increased connectivity to and from the island. Increasing production and commercialization of kava and tourism developments around the island have changed livelihoods from primarily subsistence-based to a mixed, more market-oriented model. Most households have at least one member involved in fisheries, and all households have at least one member who works in agriculture, producing occasional surpluses for sale (Medina Hidalgo et al. 2020). Most households send to market between $50 \%$ and $75 \%$ of their commercially viable produce. Land and fisheries are managed communally, and decisions about land use and fisheries are conducted using both traditional and contemporary management strategies. There is small local production of pigs and chickens, but most animal protein consumed comes from coastal fisheries and imported canned tuna. Crops grown on the island are predominantly roots, tubers, and kava, the main commercial crop. Fruits and other vegetables are produced in small quantities entirely for household consumption. Governance and decision-making processes are conducted using traditional methods such as talanoa and vanua (interrelated social, ecological, and spiritual values). Farrelly (2011) presents a detailed description of these methods and how they influence governance in Fijian villages.
Ecological subsystem

Ono Island is surrounded by the Great Astrolabe Reef and has two marine protected areas: Ulunikoro Marine Conservation Area and Great Astrolabe Lagoon Marine Protected Area. These protected areas are key to maintaining fish stocks and allowing Ono islanders to take advantage of the spillover of fish for sale and domestic consumption. Kadavu province is known for its highly fertile volcanic soils (Terry 1999). Freshwater streams supply drinking water to the villages. Most of Ono island is covered by rainforest and grassland, except for areas dedicated to food gardens and pine plantations. Mangroves fringe parts of the island but have mostly been cleared along the fronts of villages.

Ecosystem services use and delivery

Livelihoods on Ono Island are directly and indirectly linked to natural resource use and delivery. Island ecosystems directly supply their inhabitants with food, drinking water, materials for construction, and production of handicrafts. The small-scale tourism development within the area also relies on ecosystems such as the Great Astrolabe Reef as a diving attraction. Various ecosystem services were identified by members of the villages as being provided by their environment, as well as drivers of change in the provision of services (Fig. 4).

The identified drivers (Fig. 4) result from management decisions and practices in the community. The mapped relationships are a result of discussions with members of the community about changes in the provision of ecosystem services and how these changes affected the community. For example, one issue raised was that the government had established a temporary ban on sea cucumber (bêche-de-mer) fisheries to help recover the population. The ban affected families in the villages by reducing their sources of income and forcing them to increase agricultural production to compensate.

Multilayered vulnerability and resilience in the studied villages We present the results of model application for sea-level rise only, which is arguably the most important climate-linked driver of long-term change in these coastal villages (Fig. 5). The levels (low, medium, high) assigned to each attribute were derived from 
Table 2. Summary of observed and simulated changes in key climate variables for Fiji. Sources: Australian Bureau of Meteorology and CSIRO (2014), Australian Government (2015), Fiji Meteorological Service et al. (2015).

\begin{tabular}{|c|c|c|}
\hline Climate variable & Observed changes, Fiji & Projected changes ${ }^{\dagger}$, Fiji \\
\hline Surface temperature & $\begin{array}{l}\text { - Increase in maximum and minimum temperatures since } \\
1994 \\
\text { - Recorded average temperatures in Suva (capital city) have } \\
\text { increased at a rate of } 0.15^{\circ} \mathrm{C} \text { per decade } \\
\text { - Significant decreases in annual number of cool days and } \\
\text { cool nights } \\
\text { - Significant increases in annual number of warm nights }\end{array}$ & $\begin{array}{l}\text { - Temperatures projected to increase between } 0.8 \text { and } 2.0^{\circ} \mathrm{C} \text { by } 2050 \\
\text { - Rise in annual mean temperature will be accompanied by rises in } \\
\text { temperature extremes, increasing the numbers of hot days and warm } \\
\text { nights }\end{array}$ \\
\hline Precipitation & $\begin{array}{l}\text { - Precipitation patterns show notable interannual variability } \\
\text { - Existing records for 1942-2011 do not show any } \\
\text { distinguishable trends of changes in annual or seasonal } \\
\text { rainfall }\end{array}$ & $\begin{array}{l}\text { - High uncertainty for projected changes in rainfall patterns, } \\
\text { particularly for mean annual rainfall } \\
\text { - Changes range in magnitude from }-10 \% \text { to }+11 \% \text { by } 2050 \\
\text { - Wet season and extreme rain events expected to increase } \\
\text { - Drought times expected to decrease slightly }\end{array}$ \\
\hline Sea level & $\begin{array}{l}\text { - Satellite data indicate sea-level rise of } 6 \mathrm{~mm} / \mathrm{yr} \text { since } 1993 \text {, } \\
\text { which is above the global average of } 2.8 \text { to } 3.6 \mathrm{~mm} / \mathrm{yr}\end{array}$ & - Sea-level rise projected as $17-35 \mathrm{~cm} / \mathrm{yr}$ by 2050 \\
\hline Tropical cyclones & $\begin{array}{l}\text { - Affect Fiji between November and April; occasionally } \\
\text { occur in October and May in El Niño years } \\
\text { - Average of } 28 \text { cyclones/decade developed in or crossed } \\
\text { Fiji's Exclusive Economic Zone during 1969-2010 }\end{array}$ & $\begin{array}{l}\text { - Cyclone frequency expected to decrease by end of } 21 \text { st century } \\
\text { - Cyclone intensity expected to increase (wind speed and rainfall } \\
\text { intensity) }\end{array}$ \\
\hline
\end{tabular}

discussions among community members on how the different attributes were affected by sea-level rise. Each category is further described in Appendix 2. Results from each attribute were obtained by discussing with the communities which elements had driven vulnerability and resilience when responding to episodes of coastal flooding.

Fig. 4. Relationships (red arrows) between use and delivery of ecosystem services on Ono Island, Fiji. Ecosystem services and links between nonclimatic pressures and changes in services were identified by community members.

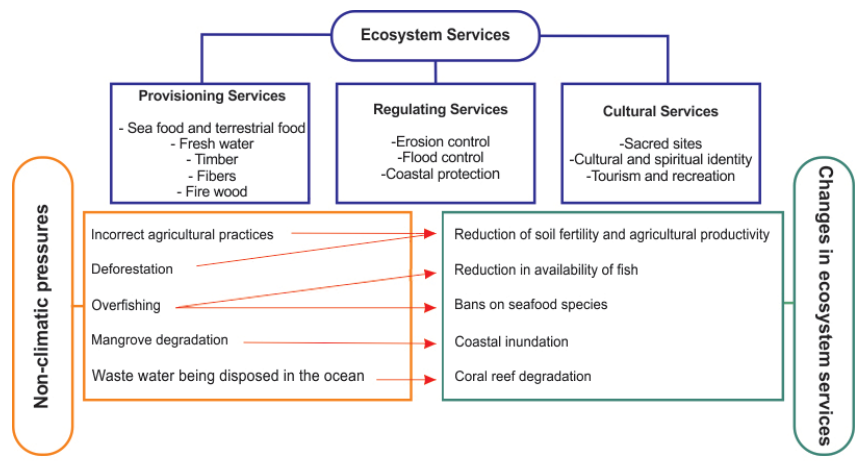

In addition, three adaptation strategies were identified as being implemented to reduce the effects of sea-level rise. Mangroves were planted in areas along the fronts of bays (not directly in front of villages); seawalls and river-bank walls were constructed in each village; and Narikoso had begun a process of upslope relocation. In implementing these strategies, elements were identified as responsible for driving vulnerability and resilience. These multiple layers of vulnerability and resilience are a product of the implementation of management decisions and the characterization of aspects influencing the different components of the model. The degree of dominance of each layer was derived from the communities' perceptions of actions that had been key in recovery after sea-flooding events and in planning for future adaptations.

\section{Dependence on external support to implement strategies: vulnerability layer}

The relocation at Narikoso began in 2011, when the village formally requested government assistance to deal with coastal flooding. This process meant having to wait for long periods of time for decisions to be made and funds to flow, which led to delays and uncertainty about how many households were being financed to move to the new site, the safety and stability of the new site, and when relocation of the entire village would be achieved. At the time of data collection in 2019, only two houses were being constructed at the new village site. Members of the community, including village elders, expressed concern about the delays and regretted that the process was conducted in a way that made them entirely dependent on external funding. Although this vulnerability layer was dominant in the past, communities expressed the need to change the approach to reduce dependency in the future.

Agency and capacity to access government support and services: resilience layer

Community members from Vabea expressed confidence about their ability to raise issues with government agencies and elicit support. After recent flooding of the village by the river in its northern part, the community notified government authorities about the problem and received support to build a river-bank wall. The wall was being constructed at the time of data collection. Workers, machinery, and materials had been sent from Suva to undertake the project, and members of the community were involved in providing supplies and food to the workers, a change from previous projects when the government only delivered materials. The capacity to access external support and the agency of village leaders was expressed as a driver of resilience that led 
Fig. 5. Drivers of vulnerability and resilience to sea-level rise identified on Ono Island, Fiji. Each component of the model is characterized to identify the different layers of vulnerability and resilience expressed in the systems in relation to sea-level rise.

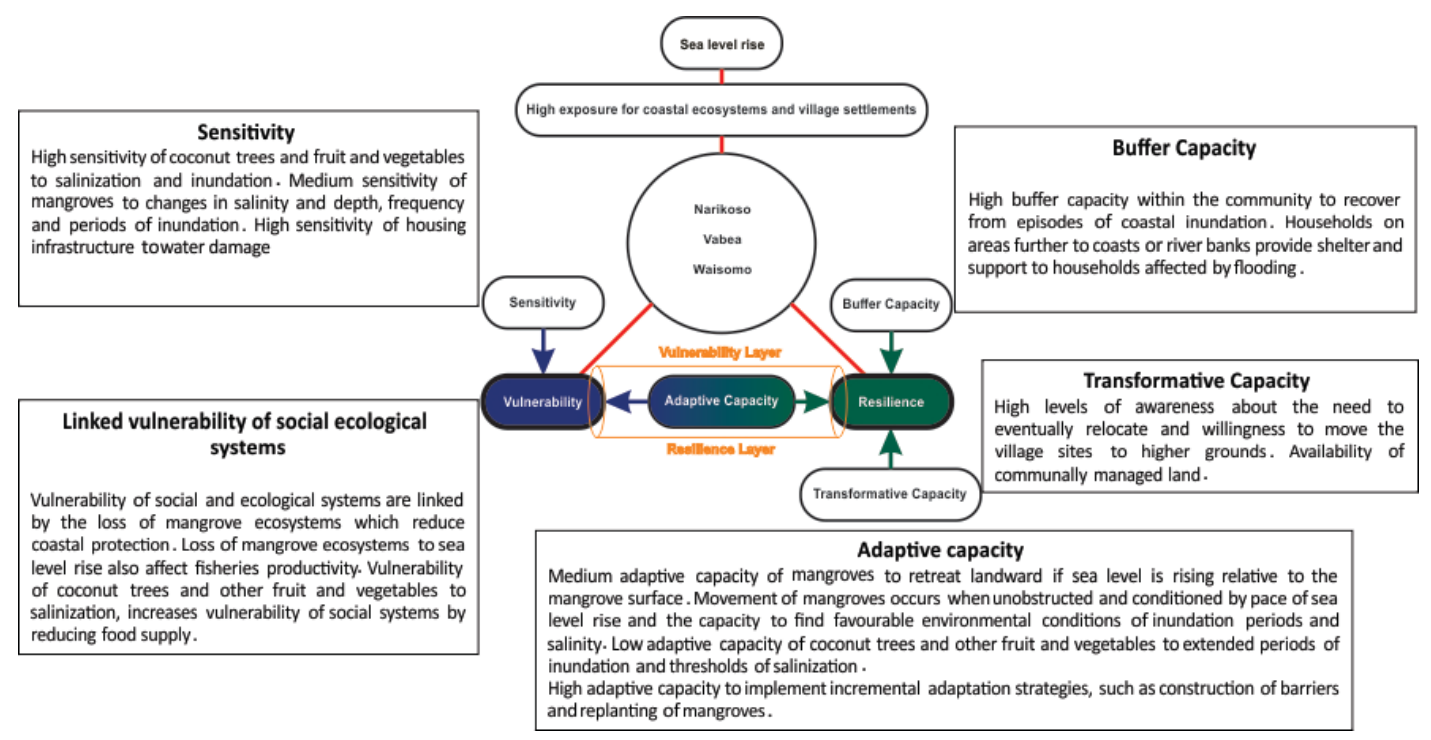

to the implementation of an adaptation strategy. Nevertheless, the recommendation to build a river-bank wall was made by the government without a feasibility or impact assessment. So even if communities have the capacity to mobilize resources, resulting adaptation strategies could potentially lead to maladaptive responses if adaptation strategies are not fully evaluated before being implemented.

\section{Lack of knowledge on how to implement strategies: vulnerability} layer

For several decades, the Ono communities had constructed seawalls and barriers to protect themselves from sea-level rise. Materials are often sent from Suva, and the walls or barriers are constructed by villagers without knowledge about their structural requirements, a common situation in rural Pacific island contexts (Nunn and Kumar 2018, Klöck and Nunn 2019). The walls and temporary barriers give the community a sense of safety that incentivizes the continuation of coastal-fringe living without foregrounding the short-term protection the barriers provide. This situation is an example of how interactions across scales affect vulnerability and resilience. Although it is unrealistic to expect local villagers to possess the engineering knowledge needed to be able to design and construct optimal seawalls, the limited capacity of the national government to oversee the execution of these strategies in remote areas means that the structures are invariably built without proper planning and supervision. Furthermore, after the barriers deteriorate, the houses built near the seawalls experience increased exposure. Ultimately, the government's promotion of this adaptation strategy does not match local capacity, resulting in the dominance of a vulnerability layer.

\section{Awareness and disposition to implement change and learn:} resilience layer

Interviews with members of the community found considerable awareness about the impacts of climate change on ecosystems and livelihoods. Although most strategies implemented to cope with changes in climate hazards have been incremental, there was a high level of community awareness about the need to implement more substantial, even transformative, strategies. As with Narikoso, for Vabea and Waisomo, it was clear that the communities would eventually need to relocate their villages and adjoining lowland farms to avoid unacceptable risks to their houses and food production. Learning from the way in which relocation has occurred in Narikoso, village elders in Vabea and Waisomo decreed that new married couples should not build their houses close to the coast. This decree will lead to a gradual and autonomously driven shift of the village from its currently exposed coastal location to less-exposed locations upslope, which has occurred elsewhere in Fiji (Nunn and Kumar 2019). The learning and awareness-raising process occurred through a reflection on the relocation process carried out in Narikoso. Prior to that experience, the position of local communities was a passive one that relied mainly on whatever solutions were recommended to them by external stakeholders such as the government and donors. In this case, the learning process is leading communities to reduce exposure progressively, as new houses are being built further from the coast.

\section{Mobilization of community resources and support: resilience layer}

Individuals identified the strength of community and family networks as key elements in helping them to cope with hazards. Families would help each other when flooding events occurred or when other climate-linked impacts unevenly affected livelihoods. This help included providing temporary housing for affected families, assisting when repairs were needed after inundation, and clearing debris after flooding events. Communal support networks have been identified in many Pacific island contexts as an example of culturally grounded resilience (Nalau et al. 2018, Walshe et al. 2018). Although this driver of resilience has been a positive influence in increasing buffer capacity, it is likely that 
under more consistent and increasing events of coastal flooding, this type of support might not be sufficient. Consequently, more transformative and adaptive capacities need to be promoted to avoid trapping the system into an undesirable state that leads to constant loss of capital.

\section{DISCUSSION}

In the application of our model to Narikoso, Vabea, and Waisomo, it became evident that communities regard their optimal future as the ability to continue living on the island and to have the means to sustain their livelihoods using local ecosystems and resources. Community members often referred to life on the island as being better than life in the capital city, Suva (or in "town" more broadly), because they had abundant resources that could be accessed for "free", meaning that they did not need cash to cover basic necessities. This situation is contrary to the often-expressed view that remote islands (and peripheral or marginal communities) are resource poor and undesirable places to live, an assumption challenged for remote communities in Fiji and elsewhere (Maru et al. 2014, Nunn et al. 2014, Korovulavula et al. 2020). Although participants acknowledged a decline in some ecosystem services (particularly fisheries and agricultural productivity) and increased impacts of climate hazards, they did not perceive these issues as being of sufficient concern to force them to leave the island.

An additional insight gained in the model's application was that most autonomous adaptation strategies used to date focused on increasing coping capacities. The process of discussing the different elements of the conceptual model with community members allowed for an additional process of learning and reflection. This process was evident when discussing the relocation in Narikoso and the realization by the other two villages that the long-term solution to the issues of coastal inundation would likely require them to relocate their villages upslope and inland. The development and application of the conceptual model highlighted several components of vulnerability and resilience that have been overlooked or undervalued when designing and implementing strategies for climate change adaptation in SIDS. One example is the need to empower local communities to implement adaptation strategies using endogenous capacities. By simultaneously identifying drivers of resilience and vulnerability, it is possible to move away from the narrative that SIDS are inherently vulnerable to risks posed by climate change and are completely dependent on assistance. Researchers and practitioners often prescribe supposedly universal and standardized indicators of resilience and vulnerability in their studies of SIDS. In contrast, we propose that the process used to apply the model is as important as the model itself. Instead of assuming a priori knowledge of what drives resilience and vulnerability, the model is used as a tool to extract this knowledge from the systems analyzed so that elements identified are as relevant and context specific as possible.

There have been several efforts to assess vulnerability and resilience in Fiji at different scales (Gravelle and Mimura 2008, Chandra and Gaganis 2016, Government of Fiji et al. 2017), yet most studies have been either too general to provide guidance for specific adaptation strategies or too tailored to the needs of individual projects or initiatives. We suggest that our model can be used as an initial diagnostic tool to support adaptation decision-making in a variety of community contexts. As donors and government agencies develop new climate adaptation initiatives requiring community-level interventions, it is important that the views and priorities of local communities are effectively incorporated at the outset (McNamara et al. 2020). This involvement is particularly relevant in overcoming barriers in the design and implementation of community and ecosystembased adaptation approaches. As noted, in developing the model, we extracted seven recommendations from the literature on aspects that need to be considered when operationalizing the concepts. Appendix 1 provides examples of how these recommendations were accounted for in the model's application. Further, although the model primarily achieves qualitative data, it can also guide the development of monitoring systems using quantitative data. Information from the model can support modeling studies on changes in resource use, effectiveness of adaptation strategies, and implementation barriers, as well as monitor drivers of vulnerability and resilience over time.

In settings with organized and structured governance systems that are culturally grounded, as is the case in rural Fiji, it is crucial to engage and empower local stakeholders in processes to develop climate change adaptation strategies. A critical aspect of the conceptual model is the potential to adapt it with the participation of stakeholders in ways that are compatible with traditional knowledge, world views, and cultural and social structures used for the coconstruction of knowledge and governance in Pacific islands and SIDS contexts (McMillen et al. 2017, Nunn et al. 2017, Weir et al. 2017, Mackay et al. 2019, Robinson 2019). The proposed model can be applied in island communities to characterize systems, i.e., not just identifying risks and vulnerabilities but also illuminating culturally anchored adaptive, coping, and transformative capacities that can be used to take advantage of opportunities. By linking both concepts to the IPCC AR5 risk model, we emphasize how the concepts can inform the development of comprehensive strategies that can use both climate change adaptation and disaster risk reduction approaches. Here, we presented only results of the analysis for sea-level rise to demonstrate how the model can be applied. When using the model as a planning support tool in different contexts, it is important to quantify risks to different hazards and how they interact with each other to define more comprehensive priorities and responses.

Future increases in climate-linked risks, added to nonclimatic pressures (e.g., increasing population density) on resources, might force communities to implement more radical transformations to sustain desired states and development aspirations. In addition, some adaptation strategies (e.g., seawall construction) may enhance coping capacities initially but increase vulnerability in the longer term. This example highlights how the prioritization and implementation of adaptation strategies sometimes create multiple layers of vulnerability and resilience that need to be managed over time as new changes in pressures and shocks unfold and are encountered. In contexts in which credible and accessible scientific information is lacking, it becomes extremely important to focus also on colearning approaches, which include the use of local and traditional knowledge together with available scientific information (Cvitanovic et al. 2016, Granderson 2017, Foley 2018). A colearning approach was achieved here by crossreferencing observed changes in climate hazards as recalled by 
participants with documented observations in climate variables. Country-level projections of changes in climate were also part of discussions with research participants about the likely magnitude of potential future changes to the systems.

\section{CONCLUSION}

We presented a conceptual model intended to facilitate operationalization of the concepts of vulnerability and resilience at a community level in a peripheral island context. Our conceptual model was applied in three coastal villages of an outer island in the Fiji archipelago using a participatory process. We identified drivers of multilayered vulnerability and resilience in the studied sites. By relating the model to specific climate hazards (focused on sea-level rise) and development objectives, it was possible to identify elements suited for use in the design and implementation of climate change adaptation strategies. Our study highlights the benefits of characterizing drivers and elements of resilience and vulnerability in support of climate adaptation planning processes prior to designing and implementing associated interventions (Joakim et al. 2015). Furthermore, by linking the vulnerability and resilience concepts, it is possible to highlight strategies to improve and use existing adaptive capacity to manage specific climate risks and take advantage of new opportunities generated by climate change.

The participating communities had incrementally implemented adaptation strategies that have led to changes in vulnerability and resilience over time. For these systems to undertake successful transformational change in the future, it is important to identify transformational capacities and understand which elements had increased resilience and which had reduced vulnerability in the past to guide the design of future initiatives and investments (Fazey et al. 2016). Because remote communities in the Pacific islands continue to experience rapid environmental change, there is a growing need to support local management and governance systems so that the communities can achieve positive and longlasting transformations. Our model has the potential to help overcome existing barriers to designing and implementing successful adaptation strategies, optimizing their effectiveness and sustainability in ways that are aligned with the unique situation of many SIDS (Klöck and Fink 2019). This outcome can be achieved by engaging local communities in the process and privileging local knowledge and governance in ways that allow them to complement current climate adaptation science and knowledge.

Responses to this article can be read online at: https://www.ecologyandsociety.org/issues/responses. php/12197

\section{Acknowledgments:}

We thank the communities of Ono Island for their support and involvement in the study. DMH is supported by an Australian Government Research Training Program Scholarship and a Commonwealth Scientific and Industrial Research Organisation (CSIRO) Postgraduate Scholarship.

\section{Data Availability:}

The data that support the findings of this study are available on request from the corresponding author, $D M H$. The data are not publicly available due to restrictions associated with the human ethics approval to conduct this study. The project followed the Australian National Statement on Ethical Conduct in Human Research, and the ethics application (A16786) was approved through the University of the Sunshine Coast Human Research Ethics Committee.

\section{LITERATURE CITED}

Adger, W. N., N. Brooks, G. Bentham, M. Agnew, and S. Eriksen. 2004. New indicators of vulnerability and adaptive capacity. Technical Report 7. Tyndall Centre for Climate Change Research, Norwich, UK.

Adger, W. N., K. Brown, D. R. Nelson, F. Berkes, H. Eakin, C. Folke, K. Galvin, L. Gunderson, M. Goulden, K. O'Brien, J. Ruitenbeek, and E. L. Tompkins. 2011. Resilience implications of policy responses to climate change. Wiley Interdisciplinary Reviews: Climate Change 2(5):757-766. https://doi.org/10.1002/ wcc. 133

Adhikari, B., and K. Taylor. 2012. Vulnerability and adaptation to climate change: a review of local actions and national policy response. Climate and Development 4(1):54-65. https://doi. org/10.1080/17565529.2012.664958

Anderies, J. M., M. A. Janssen, and E. Ostrom. 2004. A framework to analyze the robustness of social-ecological systems from an institutional perspective. Ecology and Society 9(1):18. https://doi. org/10.5751/ES-00610-090118

Australian Bureau of Meteorology and Commonwealth Scientific and Industrial Research Organisation (CSIRO). 2014. Climate variability, extremes and change in the western tropical Pacific: new science and updated country reports. Australian Bureau of Meteorology and CSIRO, Melbourne, Australia. [online] URL: https://www.pacificclimatechangescience.org/ publications/reports/climate-variability-extremes-and-change-inthe-western-tropical-pacific-2014/

Australian Government. 2015. Pacific climate change science: climate futures. Version 2.1. Australian Government, Canberra, Australia. [online] URL: https://www.pacificclimatefutures.net/ en/

Barnett, J., and C. McMichael. 2018. The effects of climate change on the geography and timing of human mobility. Population and Environment 39:339-356. https://doi.org/10.1007/s11111-018-0295-5

Barnett, J., and E. Waters. 2016. Rethinking the vulnerability of small island states: climate change and development in the Pacific Islands. Pages 731-748 in J. Grugel and D. Hammett, editors. The Palgrave handbook of international development. Palgrave Macmillan, London, UK. https://doi.org/10.1057/978-1-137-42724-3 40

Becker, M., B. Meyssignac, C. Letetrel, W. Llovel, A. Cazenave, and T. Delcroix. 2011. Sea level variations at tropical Pacific islands since 1950. Global and Planetary Change 80-81:85-98. https://doi.org/10.1016/j.gloplacha.2011.09.004 
Begum, R. A., M. S. K. Sarkar, A. H. Jaafar, and J. J. Pereira. 2014. Toward conceptual frameworks for linking disaster risk reduction and climate change adaptation. International Journal of Disaster Risk Reduction 10(A):362-373. https://doi. org/10.1016/j.ijdrr.2014.10.011

Berrouet, L. M., J. Machado, and C. Villegas-Palacio. 2018. Vulnerability of socio-ecological systems: a conceptual framework. Ecological Indicators 84:632-647. https://doi. org/10.1016/j.ecolind.2017.07.051

Biggs, R., M. Schlüter, and M. L. Schoon, editors. 2015. Principles for building resilience: sustaining ecosystem services in socialecological systems. Cambridge University Press, Cambridge, UK. https://doi.org/10.1017/CBO9781316014240

Birkmann, J., S. L. Cutter, D. S. Rothman, T. Welle, M. Garschagen, B. van Ruijven, B. O’Neill, B. L. Preston, S. Kienberger, O. D. Cardona, T. Siagian, D. Hidayati, N. Setiadi, C. R. Binder, B. Hughes, and R. Pulwarty. 2015. Scenarios for vulnerability: opportunities and constraints in the context of climate change and disaster risk. Climatic Change 133:53-68. https://doi.org/10.1007/s10584-013-0913-2

Bodin, Ö. 2017. Collaborative environmental governance: achieving collective action in social-ecological systems. Science 357(6352):eaan1114. https://doi.org/10.1126/science.aan1114

Bousquet, F., A. Botta, L. Alinovi, O. Barreteau, D. Bossio, K. Brown, P. Caron, M. d'Errico, F. DeClerck, H. Dessard, E. Enfors Kautsky, C. Fabricius, C. Folke, L. Fortmann, B. Hubert, D. Magda, R. Mathevet, R. B. Norgaard, A. Quinlan, and C. Staver. 2016. Resilience and development: mobilizing for transformation. Ecology and Society 21(3):40. https://doi.org/10.5751/ES-08754-210340

Cai, W. J., S. Borlace, M. Lengaigne, P. van Rensch, M. Collins, G. Vecchi, A. Timmermann, A. Santoso, M. J. McPhaden, L. X. Wu, M. H. England, G. J. Wang, E. Guilyardi, and F. F. Jin. 2014. Increasing frequency of extreme El Niño events due to greenhouse warming. Nature Climate Change 4:111-116. https://doi. org/10.1038/nclimate2100

Carpenter, S., B. Walker, J. M. Anderies, and N. Abel. 2001. From metaphor to measurement: resilience of what to what? Ecosystems 4:765-781. https://doi.org/10.1007/s10021-001-0045-9

Chandra, A., and P. Gaganis. 2016. Deconstructing vulnerability and adaptation in a coastal river basin ecosystem: a participatory analysis of flood risk in Nadi, Fiji Islands. Climate and Development 8(3):256-269. https://doi.org/10.1080/17565529.2015.1016884

Clare, A., R. Graber, L. Jones, and D. Conway. 2017. Subjective measures of climate resilience: What is the added value for policy and programming? Global Environmental Change 46:17-22. https://doi.org/10.1016/j.gloenvcha.2017.07.001

Cogswell, A., B. J. W. Greenan, and P. Greyson. 2018. Evaluation of two common vulnerability index calculation methods. Ocean and Coastal Management 160:46-51. https://doi.org/10.1016/j. ocecoaman.2018.03.041

Connelly, A., J. Carter, J. Handley, and S. Hincks. 2018. Enhancing the practical utility of risk assessments in climate change adaptation. Sustainability 10(5):1399. https://doi.org/10.3390/ $\underline{\text { su10051399 }}$
Cutter, S. L., L. Barnes, M. Berry, C. Burton, E. Evans, E. Tate, and J. Webb. 2008. A place-based model for understanding community resilience to natural disasters. Global Environmental Change 18(4):598-606. https://doi.org/10.1016/j.gloenvcha.2008.07.013

Cvitanovic, C., S. Crimp, A. Fleming, J. Bell, M. Howden, A. J. Hobday, M. Taylor, and R. Cunningham. 2016. Linking adaptation science to action to build food secure Pacific Island communities. Climate Risk Management 11:53-62. https://doi. org/10.1016/j.crm.2016.01.003

Darnhofer, I., J. Fairweather, and H. Moller. 2010. Assessing a farm's sustainability: insights from resilience thinking. International Journal of Agricultural Sustainability 8(3):186-198. https://doi.org/10.3763/ijas.2010.0480

Davidson, J. L., C. Jacobson, A. Lyth, A. Dedekorkut-Howes, C. L. Baldwin, J. C. Ellison, N. J. Holbrook, M. J. Howes, S. SerraoNeumann, L. Singh-Peterson, and T. F. Smith. 2016. Interrogating resilience: toward a typology to improve its operationalization. Ecology and Society 21(2):27. https://doi. org/10.5751/ES-08450-210227

Dixon, J. L., and L. C. Stringer. 2015. Towards a theoretical grounding of climate resilience assessments for smallholder farming systems in sub-Saharan Africa. Resources 4(1):128-154. https://doi.org/10.3390/resources4010128

Douxchamps, S., L. Debevec, M. Giordano, and J. Barron. 2017. Monitoring and evaluation of climate resilience for agricultural development - a review of currently available tools. World Development Perspectives 5:10-23. https://doi.org/10.1016/j. $\underline{w d p .2017 .02 .001}$

Farrelly, T. A. 2011. Indigenous and democratic decision-making: issues from community-based ecotourism in the Boumā National Heritage Park, Fiji. Journal of Sustainable Tourism 19(7):817-835. https://doi.org/10.1080/09669582.2011.553390

Farrelly, T., and U. Nabobo-Baba. 2014. Talanoa as empathic apprenticeship. Asia Pacific Viewpoint 55:319-330. https://doi. org/10.1111/apv.12060

Fazey, I., R. M. Wise, C. Lyon, C. Câmpeanu, P. Moug, and T. E. Davies. 2016. Past and future adaptation pathways. Climate and Development 8(1):26-44. https://doi.org/10.1080/17565529.2014.989192

Fiji Bureau of Statistics. 2018.2017 population and housing census. Fiji Bureau of Statistics, Suva, Fiji. [online] URL: https://www. statsfiji.gov.fj/index.php/census-2017/census-2017-release-1

Fiji Meteorological Service, Australian Bureau of Meteorology, and Commonwealth Scientific and Industrial Research Organisation. 2015. Current and future climate of the Fiji Islands. Pacific-Australia Climate Change Science and Adaptation Plannning Program, Melbourne, Australia. [online] URL: https:// www.pacificclimatechangescience.org/wp-content/ uploads/2013/06/1_PACCSAP-Fiji-11pp_WEB.pdf

Foley, A. M. 2018. Climate impact assessment and "islandness": challenges and opportunities of knowledge production and decision-making for Small Island Developing States. International Journal of Climate Change Strategies and Management 10(2):289-302. https://doi.org/10.1108/IJCCSM-06-2017-0142 
Folke, C. 2006. Resilience: the emergence of a perspective for social-ecological systems analyses. Global Environmental Change 16(3):253-267. https://doi.org/10.1016/j.gloenvcha.2006.04.002

Folke, C. 2016. Resilience (republished). Ecology and Society 21 (4):44. https://doi.org/10.5751/ES-09088-210444

Folke, C., R. Biggs, A. V. Norström, B. Reyers, and J. Rockström. 2016. Social-ecological resilience and biosphere-based sustainability science. Ecology and Society 21(3):41. https://doi.org/10.5751/ ES-08748-210341

Folke, C., S. R. Carpenter, B. Walker, M. Scheffer, T. Chapin, and J. Rockström. 2010. Resilience thinking: integrating resilience, adaptability and transformability. Ecology and Society 15(4):20. https://doi.org/10.5751/ES-03610-150420

Gallopín, G. C. 2006. Linkages between vulnerability, resilience, and adaptive capacity. Global Environmental Change 16 (3):293-303. https://doi.org/10.1016/j.gloenvcha.2006.02.004

Government of Fiji, World Bank, and Global Facility for Disaster Reduction and Recovery. 2017. Climate vulnerability assessment: making Fiji climate resilient. World Bank, Washington, D.C., USA. [online] URL: https://documents.worldbank.org/en/ publication/documents-reports/documentdetail/163081509454340771/ climate-vulnerability-assessment-making-fiji-climate-resilient

Granderson, A. A. 2017. The role of traditional knowledge in building adaptive capacity for climate change: perspectives from Vanuatu. Weather, Climate, and Society 9(3):545-561. https://doi. org/10.1175/WCAS-D-16-0094.1

Gravelle, G., and N. Mimura. 2008. Vulnerability assessment of sea-level rise in Viti Levu, Fiji Islands. Sustainability Science 3:171-180. https://doi.org/10.1007/s11625-008-0052-2

Green, M. 2016. Contested territory. Nature Climate Change 6:817-820. https://doi.org/10.1038/nclimate3112

Grose, M. R., J. N. Brown, S. Narsey, J. R. Brown, B. F. Murphy, C. Langlais, A. S. Gupta, A. F. Moise, and D. B. Irving. 2014. Assessment of the CMIP5 global climate model simulations of the western tropical Pacific climate system and comparison to CMIP3. International Journal of Climatology 34(12):3382-3399. https://doi.org/10.1002/joc.3916

Haimes, Y. Y. 2012. Strategic preparedness for recovery from catastrophic risks to communities and infrastructure systems of systems. Risk Analysis 32(11):1834-1845. https://doi.org/10.1111/ j.1539-6924.2012.01930.x

Hay, J. E., and N. Mimura. 2013. Vulnerability, risk and adaptation assessment methods in the Pacific Islands region: past approaches, and considerations for the future. Sustainability Science 8:391-405. https://doi.org/10.1007/s11625-013-0211-y

Hinkel, J. 2011. "Indicators of vulnerability and adaptive capacity": towards a clarification of the science-policy interface. Global Environmental Change 21(1):198-208. https://doi. org/10.1016/j.gloenvcha.2010.08.002

Holling, C. S. 1973. Resilience and stability of ecological systems. Annual Review of Ecology and Systematics 4:1-23. https://doi. org/10.1146/annurev.es.04.110173.000245
Iniesta-Arandia, I., M. García-Llorente, P. A. Aguilera, C. Montes, and B. Martín-López. 2014. Socio-cultural valuation of ecosystem services: uncovering the links between values, drivers of change, and human well-being. Ecological Economics 108:36-48. https://doi.org/10.1016/j.ecolecon.2014.09.028

Intergovernmental Panel on Climate Change (IPCC). 2007. Climate change 2007: impacts, adaptation, and vulnerability. Contribution of working group II to the fourth assessment report of the Intergovernmental Panel on Climate Change. Cambridge University Press, Cambridge, UK. [online] URL: https://www. ipcc.ch/report/ar4/wg2/

Intergovernmental Panel on Climate Change (IPCC). 2014a. Climate change 2014: impacts, adaptation, and vulnerability. Part A: global and sectoral aspects. Contribution of Working Group II to the Fifth Assessment Report of the Intergovernmental Panel on Climate Change. Cambridge University Press, Cambridge, UK. [online] URL: https://www.ipcc.ch/report/ar5/wg2/

Intergovernmental Panel on Climate Change (IPCC). $2014 b$. Climate change 2014: impacts, adaptation, and vulnerability. Part $B$ : regional aspects. Working Group II Contribution to the IPCC Fifth Assessment Report. Cambridge University Press, Cambridge, UK. [online] URL: https://www.ipcc.ch/report/ar5/ wg2l

Irving, D. B., S. E. Perkins, J. R. Brown, A. S. Gupta, A. F. Moise, B. F. Murphy, L. C. Muir, R. A. Colman, S. B. Power, F. P. Delage, and J. N. Brown. 2011. Evaluating global climate models for the Pacific island region. Climate Research 49:169-187. https://doi. org/10.3354/cr01028

Joakim, E. P., L. Mortsch, and G. Oulahen. 2015. Using vulnerability and resilience concepts to advance climate change adaptation. Environmental Hazards 14(2):137-155. https://doi. org/10.1080/17477891.2014.1003777

Johnson, J. E., D. J. Welch, J. A. Maynard, J. D. Bell, G. Pecl, J. Robins, and T. Saunders. 2016. Assessing and reducing vulnerability to climate change: moving from theory to practical decision-support. Marine Policy 74:220-229. https://doi. org/10.1016/j.marpol.2016.09.024

Kelman, I. 2017. Linking disaster risk reduction, climate change, and the sustainable development goals. Disaster Prevention and Management 26(3):254-258. https://doi.org/10.1108/DPM-02-2017-0043

Kerner, D. A., and J. S. Thomas. 2014. Resilience attributes of social-ecological systems: framing metrics for management. Resources 3(4):672-702. https://doi.org/10.3390/resources3040672

Klöck, C., and M. Fink, editors. 2019. Dealing with climate change on small islands: towards effective and sustainable adaptation? Göttingen University Press, Göttingen, The Netherlands. https:// doi.org/10.17875/gup2019-1208

Klöck, C., and P. D. Nunn. 2019. Adaptation to climate change in small island developing states: a systematic literature review of academic research. Journal of Environment and Development 28 (2):196-218. https://doi.org/10.1177/1070496519835895

Korovulavula, I., P. D. Nunn, R. Kumar, and T. Fong. 2020. Peripherality as key to understanding opportunities and needs 
for effective and sustainable climate-change adaptation: a case study from Viti Levu Island, Fiji. Climate and Development 12 (10):888-898. https://doi.org/10.1080/17565529.2019.1701972

Lei, Y., J. Wang, Y. Yue, H. Zhou, and W. Yin. 2014. Rethinking the relationships of vulnerability, resilience, and adaptation from a disaster risk perspective. Natural Hazards 70:609-627. https:// doi.org/10.1007/s11069-013-0831-7

Levin, S., T. Xepapadeas, A.-S. Crépin, J. Norberg, A. de Zeeuw, C. Folke, T. Hughes, K. Arrow, S. Barrett, G. Daily, P. Ehrlich, N. Kautsky, K.-G. Mäler, S. Polasky, M. Troell, J. R. Vincent, and B. Walker. 2013. Social-ecological systems as complex adaptive systems: modeling and policy implications. Environment and Development Economics 18(2):111-132. https://doi.org/10.1017/ $\underline{\mathrm{S} 1355770 \mathrm{X} 12000460}$

Loo, C. 2014. The role of community participation in climate change assessment and research. Journal of Agricultural and Environmental Ethics 27:65-85. https://doi.org/10.1007/s10806-013-9452-0

Mackay, S., R. Brown, M. Gonelevu, N. Pelesikoti, T. Kocovanua, R. Iaken, F. Iautu, L. Tuiafitu-Malolo, S. Fulivai, M. Lepa, and B. Mackey. 2019. Overcoming barriers to climate change information management in small island developing states: lessons from Pacific SIDS. Climate Policy 19(1):125-138. https:// doi.org/10.1080/14693062.2018.1455573

Marshall, N. A., C. J. Stokes, N. P. Webb, P. A. Marshall, and A. J. Lankester. 2014. Social vulnerability to climate change in primary producers: a typology approach. Agriculture, Ecosystems and Environment 186:86-93. https://doi.org/10.1016/j.agee.2014.01.004

Marshall, N. A., R. C. Tobin, P. A. Marshall, M. Gooch, and A. J. Hobday. 2013. Social vulnerability of marine resource users to extreme weather events. Ecosystems 16:797-809. https://doi. org/10.1007/s10021-013-9651-6

Maru, Y. T., M. Stafford Smith, A. Sparrow, P. F. Pinho, and O. P. Dube. 2014. A linked vulnerability and resilience framework for adaptation pathways in remote disadvantaged communities. Global Environmental Change 28:337-350. https://doi.org/10.1016/ j.gloenvcha.2013.12.007

McMillen, H., T. Ticktin, and H. K. Springer. 2017. The future is behind us: traditional ecological knowledge and resilience over time on Hawai'i Island. Regional Environmental Change 17:579-592. https://doi.org/10.1007/s10113-016-1032-1

McNamara, K. E., R. Clissold, R. Westoby, A. E. PiggottMcKellar, R. Kumar, T. Clarke, F. Namoumou, F. Areki, E. Joseph, O. Warrick, and P. D. Nunn. 2020. An assessment of community-based adaptation initiatives in the Pacific Islands. Nature Climate Change 10:628-639. https://doi.org/10.1038/ s41558-020-0813-1

Medina Hidalgo, D., I. Witten, P. D. Nunn, S. Burkhart, J. R. Bogard, H. Beazley, and M. Herrero. 2020. Sustaining healthy diets in times of change: linking climate hazards, food systems and nutrition security in rural communities of the Fiji Islands. Regional Environmental Change 20:73. https://doi.org/10.1007/ s10113-020-01653-2

Metcalf, S. J., E. I. van Putten, S. Frusher, N. A. Marshall, M. Tull, N. Caputi, M. Haward, A. J. Hobday, N. J. Holbrook, S. M.
Jennings, G. T. Pecl, and J. L. Shaw. 2015. Measuring the vulnerability of marine social-ecological systems: a prerequisite for the identification of climate change adaptations. Ecology and Society 20(2):35. https://doi.org/10.5751/ES-07509-200235

Miller, F., H. Osbahr, E. Boyd, F. Thomalla, S. Bharwani, G. Ziervogel, B. Walker, J. Birkmann, S. van der Leeuw, J. Rockström, J. Hinkel, T. Downing, C. Folke, and D. Nelson. 2010. Resilience and vulnerability: complementary or conflicting concepts? Ecology and Society 15(3):11. https://doi.org/10.5751/es-03378-150311

Nalau, J., S. Becken, J. Schliephack, M. Parsons, C. Brown, and B. Mackey. 2018. The role of Indigenous and traditional knowledge in ecosystem-based adaptation: a review of the literature and case studies from the Pacific Islands. Weather, Climate, and Society 10(4):851-865. https://doi.org/10.1175/ WCAS-D-18-0032.1

Nunn, P., and R. Kumar. 2018. Understanding climate-human interactions in small island developing states (SIDS): implications for future livelihood sustainability. International Journal of Climate Change Strategies and Management 10(2):245-271. https://doi.org/10.1108/IJCCSM-01-2017-0012

Nunn, P., and R. Kumar. 2019. Measuring peripherality as a proxy for autonomous community coping capacity: a case study from Bua Province, Fiji Islands, for improving climate change adaptation. Social Sciences 8(8):225. https://doi.org/10.3390/ $\underline{\text { socsci } 8080225}$

Nunn, P. D., W. Aalbersberg, S. Lata, and M. Gwilliam. 2014. Beyond the core: community governance for climate-change adaptation in peripheral parts of Pacific Island countries. Regional Environmental Change 14:221-235. https://doi. org/10.1007/s10113-013-0486-7

Nunn, P. D., and K. E. McNamara. 2019. Failing adaptation in island contexts: the growing need for transformational change. Pages 19-44 in C. Klöck and M. Fink, editors. Dealing with climate change on small islands: towards effective and sustainable adapation? Göttingen University Press, Göttingen, The Netherlands. https://doi.org/10.17875/gup2019-1210

Nunn, P. D., J. Runman, M. Falanruw, and R. Kumar. 2017. Culturally grounded responses to coastal change on islands in the Federated States of Micronesia, northwest Pacific Ocean. Regional Environmental Change 17:959-971. https://doi. org/10.1007/s10113-016-0950-2

Nurse, L. A., R. F. McLean, J. Agard, L. P. Briguglio, V. DuvatMagnan, N. Pelesikoti, E. Tompkins, and A. Webb. 2014. Small islands. Pages 1613-1654 in Intergovernmental Panel on Climate Change (V. R. Barros, C. B. Field, D. J. Dokken, M. D. Mastrandrea, K. J. Mach, T. E. Bilir, M. Chatterjee, K. L. Ebi, Y. O. Estrada, R. C. Genova, B. Girma, E. S. Kissel, A. N. Levy, S. MacCracken, P. R. Mastrandrea, and L. L. White, editors). Climate change 2014: impacts, adaptation, and vulnerability. Part B: regional aspects. Contribution of Working Group II to the Fifth Assessment Report of the Intergovernmental Panel on Climate Change. Cambridge University Press, Cambridge, UK. [online] URL: https://www.ipcc.ch/site/assets/uploads/2018/02/ WGIIAR5-Chap29 FINAL.pdf

O’Brien, K., S. Eriksen, L. P. Nygaard, and A. Schjolden. 2007. Why different interpretations of vulnerability matter in climate 
change discourses. Climate Policy 7(1):73-88. https://doi. org/10.1080/14693062.2007.9685639

Papadimitriou, L., I. P. Holman, R. Dunford, and P. A. Harrison. 2019. Trade-offs are unavoidable in multi-objective adaptation even in a post-Paris Agreement world. Science of the Total Environment 696:134027. https://doi.org/10.1016/j.scitotenv.2019.134027

Paré, G., M.-C. Trudel, M. Jaana, and S. Kitsiou. 2015. Synthesizing information systems knowledge: a typology of literature reviews. Information and Management 52(2):183-199. https://doi.org/10.1016/j.im.2014.08.008

Pearson, J., K. E. McNamara, and P. D. Nunn. 2019. Genderspecific perspectives of mangrove ecosystem services: case study from Bua Province, Fiji Islands. Ecosystem Services 38:100970. https://doi.org/10.1016/j.ecoser.2019.100970

Piggott-McKellar, A. E., K. E. McNamara, and P. D. Nunn. 2020. Who defines "good" climate change adaptation and why it matters: a case study from Abaiang Island, Kiribati. Regional Environmental Change 20:43. https://doi.org/10.1007/s10113-020-01614-9

Preston, B. L., E. J. Yuen, and R. M. Westaway. 2011. Putting vulnerability to climate change on the map: a review of approaches, benefits, and risks. Sustainability Science 6:177-202. https://doi.org/10.1007/s11625-011-0129-1

Quandt, A. 2018. Measuring livelihood resilience: the household livelihood resilience approach (HLRA). World Development 107:253-263. https://doi.org/10.1016/j.worlddev.2018.02.024

Robinson, S. 2019. Mainstreaming climate change adaptation in small island developing states. Climate and Development 11 (1):47-59. https://doi.org/10.1080/17565529.2017.1410086

Shah, S. H., L. C. Angeles, and L. M. Harris. 2017. Worlding the intangibility of resilience: the case of rice farmers and waterrelated risk in the Philippines. World Development 98:400-412. https://doi.org/10.1016/j.worlddev.2017.05.004

Sofer, M. 2007. Yaqona and the Fijian periphery revisited. Asia Pacific Viewpoint 48(2):234-249. https://doi.org/10.1111/ j.1467-8373.2007.00342.x

Speranza, C. I. 2013. Buffer capacity: capturing a dimension of resilience to climate change in African smallholder agriculture. Regional Environmental Change 13:521-535. https://doi. org/10.1007/s10113-012-0391-5

Tanner, T., D. Lewis, D. Wrathall, R. Bronen, N. Cradock-Henry, S. Huq, C. Lawless, R. Nawrotzki, V. Prasad, M. A. Rahman, R. Alaniz, K. King, K. McNamara, M. Nadiruzzaman, S. HenlyShepard, and F. Thomalla. 2015. Livelihood resilience in the face of climate change. Nature Climate Change 5:23-26. https://doi. org/10.1038/nclimate2431

Terry, J. P. 1999. Kadavu Island, Fiji: fluvial studies of a volcanic island in the humid tropical South Pacific. Singapore Journal of Tropical Geography 20(1):86-98. https://doi.org/10.1111/1467-9493.00045

Thiault, L., P. Marshall, S. Gelcich, A. Collin, F. Chlous, and J. Claudet. 2018. Mapping social-ecological vulnerability to inform local decision making. Conservation Biology 32(2):447-456. https://doi.org/10.1111/cobi.12989
Walker, B., C. S. Holling, S. R. Carpenter, and A. Kinzig. 2004. Resilience, adaptability and transformability in social-ecological systems. Ecology and Society 9(2):5. https://doi.org/10.5751/ ES-00650-090205

Walker, B. H., L. H. Gunderson, A. P. Kinzig, C. Folke, S. R. Carpenter, and L. Schultz. 2006. A handful of heuristics and some popositions for uderstanding rsilience in scial-eological systems. Ecology and Society 11(1):13. https://doi.org/10.5751/es-01530-110113

Walshe, R. A., D. C. Seng, A. Bumpus, and J. Auffray. 2018. Perceptions of adaptation, resilience and climate knowledge in the Pacific: the cases of Samoa, Fiji and Vanuatu. International Journal of Climate Change Strategies and Management 10 (2):303-322. https://doi.org/10.1108/IJCCSM-03-2017-0060

Warrick, O., W. Aalbersberg, P. Dumaru, R. McNaught, and K. Teperman. 2017. The 'Pacific Adaptive Capacity Analysis Framework': guiding the assessment of adaptive capacity in Pacific island communities. Regional Environmental Change 17:1039-1051. https://doi.org/10.1007/s10113-016-1036-x

Weir, T., L. Dovey, and D. Orcherton. 2017. Social and cultural issues raised by climate change in Pacific Island countries: an overview. Regional Environmental Change 17:1017-1028. https:// doi.org/10.1007/s10113-016-1012-5

Wilson, G. A., and O. J. Wilson. 2019. Assessing the resilience of human systems: a critical evaluation of universal and contextual resilience variables. Resilience 7(2):126-148. https://doi. org/10.1080/21693293.2018.1539205

Wise, R. M., I. Fazey, M. Stafford Smith, S. E. Park, H. C. Eakin, E. R. M. Archer Van Garderen, and B. Campbell. 2014. Reconceptualising adaptation to climate change as part of pathways of change and response. Global Environmental Change 28:325-336. https://doi.org/10.1016/j.gloenvcha.2013.12.002 


\section{Appendix 1}

This appendix expands on the description of seven recommendations that were identified from a comprehensive literature review, and which need to be considered when applying vulnerability and resilience frameworks. This review was conducted using scientific databases to identify peer-reviewed publications in the past 10 years focused on the operationalization of the concepts of vulnerability and resilience, with an emphasis on their use to support climate change adaptation planning in social-ecological systems (SES).

We use the STARLITE framework (Booth 2006) to report the approach and characteristics of the review conducted.

\begin{tabular}{|c|c|}
\hline Element & Explanation \\
\hline $\mathrm{S}=$ Sampling Strategy & $\begin{array}{l}\text { Purposive sampling identified for climate } \\
\text { change adaptation applications in SES. } \\
\text { Studies were sorted by relevance and } \\
\text { sampling was conducted until no more } \\
\text { relevant articles appeared in a search results } \\
\text { page. }\end{array}$ \\
\hline $\mathrm{T}=$ Type of studies & $\begin{array}{l}\text { Studies included were reviews, case studies } \\
\text { and conceptual papers. }\end{array}$ \\
\hline $\mathrm{A}=$ Approaches & $\begin{array}{l}\text { Hand search for relevance to the topic and } \\
\text { research questions. }\end{array}$ \\
\hline $\mathrm{R}=$ Range of years & Ten years (2009 to 2019). \\
\hline $\mathrm{L}=$ Limits & $\begin{array}{l}\text { Only documents available in full-text online } \\
\text { and in English were considered. }\end{array}$ \\
\hline $\mathrm{I}=$ Inclusion and exclusions & $\begin{array}{l}\text { Inclusion of articles was limited to studies in } \\
\text { which the concepts were used in support of } \\
\text { climate adaptation planning, the studies } \\
\text { referred to SES the application was relevant } \\
\text { to planning processes at the local or } \\
\text { community scales. }\end{array}$ \\
\hline $\mathrm{T}=$ Terms used & $\begin{array}{l}\text { Terms used were "vulnerability" AND } \\
\text { "resilience" AND "community", "assess*" } \\
\text { AND "climate change" }\end{array}$ \\
\hline $\mathrm{E}=$ Electronic sources & $\begin{array}{l}\text { Databases used to conduct the search were } \\
\text { SCOPUS and Web of Science. }\end{array}$ \\
\hline
\end{tabular}

The following 7 recommendations summarize the results of the review and point to the ways in which the recommendations were utilised in the case study. 


\section{Frame the analysis to tangible development outcomes and define a purpose}

Vulnerability and resilience should be referred to as a qualities that allow or hinder the achievement of one or multiple development outcomes (Fröde et al. 2013). Initiatives aimed at increasing a system's resilience or reducing vulnerability will be conducive to the achievement of development goals, while dealing with climate change (Castells-Quintana et al. 2018). For example, a development outcome could be the achievement of food and nutritional security or increasing household incomes. Since not all adaptation strategies will be conducive to achieving multiple goals, it is important to analyse potential trade-offs (Donner and Webber 2014, Johnson et al. 2016, Hsu et al. 2017). Resilience is the capacity that allows the system to achieve the development outcome under likely shocks or pressures, while vulnerability drivers could reduce the capacity of the system to achieve the same outcome. In the application of the conceptual model it is important that a development outcome is clearly identified and communicated. This means identifying if the model is being used to define a baseline, as part of a monitoring and evaluation system, or as part of an adaptation planning process.

\subsection{How was this recommendation applied in the study?}

In the application of the conceptual framework two development objectives were identified through focus group discussions with the communities: (i) securing sources of livelihood and income and (ii) being able to sustain households and current way of living in the villages in the face of the manifest climate-driven environmental changes. These objectives were prioritized by participants as the two main driving forces that concerned them in their plans for the development of their villages. This means that in the study vulnerability and resilience are not framed as the outcomes of interventions, but as attributes that can be modified to allow the systems to achieve those two development goals under shocks and pressures. The purpose of the study was twofold, from a research perspective, the study aimed to test and improve the conceptual framework and from a practical perspective the aim was to assess adaptation planning processes in the villages by reflecting on the management and adaptation decisions carried out, and how they have amplified or diminished resilience and vulnerability drivers.

\section{Integrate subjective perspectives}

Perceptions of shocks, desirable states and thresholds are all relative to subjective values, hence these should be understood and integrated into the analysis (Béné et al. 2016, Clare et al. 2017). Subjective perspectives can be gathered through participatory methods designed for the collection of qualitative data in a way that is culturally appropriate and accepted. This allows for vulnerability and resilience drivers to be context specific and to capture what stakeholders value as being at risk and needs to be preserved.

\subsection{How was this recommendation applied in the study?}

The way in which questions were asked in the study and the community engagement methods used (such as Talanoa) allowed for researchers to give priority to the subjective perspectives of the participants. Instead of developing pre-conceived ideas of what drives vulnerability and resilience in those settings and trying to measure it, the framework was used 
to gather those perspectives and discuss them with community members. This also allowed participants to define limits of the system themselves (e.g. the reluctance of relocating communities outside the island), and to understand what communities value and what their aspirations are.

\section{Promote systemic analysis and represent complex relationships}

The application of the model should catalyse a better understanding of system dynamics and address the complex relationships between attributes, assets and processes within the system being analysed (Darnhofer et al. 2010, Resilience Alliance 2010, Liu 2014). This is a key aspect when applying the model in the context of SES. Research processes would benefit from integrating multiple disciplines, as assessing only social or environmental aspects of the system will likely misrepresent risk and potential impacts (Metcalf et al. 2015, Quinlan et al. 2016).

\subsection{How was this recommendation applied in the study?}

In the application of the conceptual framework researchers engaged in transect walks and participated in daily activities of life in the villages, such as fishing, farming and village celebrations. This research approach provided a better understanding of the way in which communities interact with the environment and the definition of ecosystem services use, and delivery and how they are affected by different management decisions. This is something that can then be further developed by establishing local monitoring systems to assess the status of key ecosystems such as mangroves and reefs.

\section{Specify shocks and stressors}

The purpose of the model is to support climate adaptation planning processes; therefore, climate hazards and shocks should be explicitly identified (Wolf et al. 2013, Liu 2014, Weis et al. 2016). Through this process is possible to answer the question "resilience and vulnerability to what?" implying shocks need to be defined and quantified. It is also important to determine the magnitude and direction of changes in key climatic variables and if the analysis is being conducted under current climate variability conditions or including future climate change projections (Jurgilevich et al. 2017). This reinforces the need for detailed and specific impact models and information to strengthen the understanding of how specific shocks could impact the systems being analysed. Clearly defining and identifying shocks and stressors will contribute to determine how climate change might change the magnitude of shocks and how that could shift tipping points and vulnerability and resilience attributes.

\subsection{How was this recommendation applied in the study?}

In the study, shocks and stressors were defined both by community members and by reviewing available literature on downscaled projections of changes in climate attributes. When discussing drivers of vulnerability and resilience the discussions were focused on how those related to the identified climate hazards. Additional non-climatic stressors were also included in the discussion, such as difficulties associated with market access and changes in fisheries regulations that affected the systems. Consequently, the different elements of the model were 
discussed in the context of each hazard and interactions between climate and non-climatic shocks.

\section{Define desirable and undesirable states}

A system can return to an undesirable state of stability after a shock, hence it is important to establish what is desirable or not for each system (Shah et al. 2017). This decision needs to be through participatory processes, allowing the perspectives of stakeholders to be captured (Clare et al. 2017). It is also important to determine what can be acceptable levels of residual risk that cannot be covered by planned adaptation strategies (Kelman et al. 2015).

\subsection{How was this recommendation applied in the study?}

The recommendation to define desirable and undesirable states was included when discussing community members' goals for the villages, and how they envisioned their communities should develop. This topic was particularly relevant when discussing community relocation. Participants expressed the willingness to relocate within the island but were more reluctant to options of relocation outside their traditional lands and clan ties. This finding suggests that there are some residual risks that need to be managed, even after communities relocate to the interior of the island.

\section{Capture interaction across time and scales:}

Resilience and vulnerability can be expressed at different scales (individual, household or community for example) (Johnson et al. 2016, Otto et al. 2017). Therefore, when applying the model, it should be acknowledged in a transparent way for which scales the results of the assessment are valid and relevant. To achieve this aim, the boundaries of the system that is being analysed need to be defined. However, it is relevant to recognize when changes outside the system being studied could have an impact on resilience and vulnerability drivers (Thiault et al. 2018). Drivers of vulnerability and resilience are also dynamic and will change over time. Assessments need to be able to acknowledge changes in time and be transparent about the moments in time the data is collected and what they can represent or not (Bousquet et al. 2016). Some information might only be relevant for specific timeframes. It must be understood that as conditions change due to internal and external pressures in a system, the assessed resilience and vulnerability will also change.

\subsection{How was this recommendation applied in the study?}

Because of the limitation in downscaled climate projections, the study was limited to discuss general scenarios where existing hazards could increase. For example, that sea level rise continues to exacerbate coastal erosion and coastal flooding. When discussing climate hazards, the study was limited to information recalled by participants on changes in climate hazards in the past 10 years. The cyclone that occurred in 1979 was the only event that participants referred to that was outside of the 10-year period, probably because of the devastating effect it had on the island. The study has also limited its conclusions and recommendations to the 3 villages that were included in the study. While it is suggested that the model can be applied and adapted to similar settings, the recommendations are limited to 
the communities in which the study was conducted and are not aimed to be generalized to all remote island settings in the Pacific. In the study we also discuss cross-scale interactions of villages receiving support from national level governments and donors and regulation at the national level that affects governance of resources at the local levels.

\section{Capture heterogeneity:}

Even households or communities with similar levels of exposure to shocks can express different levels of vulnerability and resilience (Baptiste and Kinlocke 2016, Weis et al. 2016). While the application of the model will imply different levels of aggregation of information, particularly when the model is applied at larger scales, a careful balance should be applied to ensure that the model is not being used to make broad generalizations of communities or populations.

\subsection{How was this recommendation applied in the study?}

In line with the previous recommendation, the study was used to characterize drivers of vulnerability and resilience in three neighbouring villages. While there might be some intravillage heterogeneities that could modify drivers of vulnerability and resilience ( for example household level networks with other households outside of the villages exchanging goods and services), this was outside of the scope of the study and the results presented are to be interpreted only in the context of the studied villages. 


\section{Literature cited}

Baptiste, A. K., and R. Kinlocke. 2016. We are not all the same!: Comparative climate change vulnerabilities among fishers in Old Harbour Bay, Jamaica. Geoforum 73:47-59.

Béné, C., R. M. Al-Hassan, O. Amarasinghe, P. Fong, J. Ocran, E. Onumah, R. Ratuniata, T. V. Tuyen, J. A. McGregor, and D. J. Mills. 2016. Is resilience socially constructed? Empirical evidence from Fiji, Ghana, Sri Lanka, and Vietnam. Global Environmental Change 38:153-170.

Booth, A. 2006. "Brimful of STARLITE": toward standards for reporting literature searches. Journal of the Medical Library Association 94:421.

Bousquet, F., A. Botta, L. Alinovi, O. Barreteau, D. Bossio, K. Brown, P. Caron, M. d'Errico, F. DeClerck, H. Dessard, E. E. Kautsky, C. Fabricius, C. Folke, L. Fortmann, B. Hubert, D. Magda, R. Mathevet, R. B. Norgaard, A. Quinlan, and C. Staver. 2016. Resilience and development: mobilizing for transformation. Ecology and Society 21:18.

Castells-Quintana, D., M. D. P. Lopez-Uribe, and T. K. J. McDermott. 2018. Adaptation to climate change: A review through a development economics lens. World Development 104:183-196.

Clare, A., R. Graber, L. Jones, and D. Conway. 2017. Subjective measures of climate resilience: What is the added value for policy and programming? Global Environmental Change 46:17-22.

Darnhofer, I., J. Fairweather, and H. Moller. 2010. Assessing a farm's sustainability: insights from resilience thinking. International Journal of Agricultural Sustainability 8:186-198.

Donner, S., and S. Webber. 2014. Obstacles to climate change adaptation decisions: a case study of sea-level rise and coastal protection measures in Kiribati. Sustainability Science 9:331-345.

Fröde, A., M. Scholze, and N. Manasfi. 2013. Taking a climate perspective on development: GIZ's climate proofing for development approach. Climate and Development 5:160-164.

Hsu, A., A. Weinfurter, and K. Xu. 2017. Aligning subnational climate actions for the new post-Paris climate regime. Climatic Change 142:419-432.

Johnson, J. E., D. J. Welch, J. A. Maynard, J. D. Bell, G. Pecl, J. Robins, and T. Saunders. 2016. Assessing and reducing vulnerability to climate change: moving from theory to practical decision-support. Marine Policy 74:220-229.

Jurgilevich, A., A. Räsänen, F. Groundstroem, and S. J. E. R. L. Juhola. 2017. A systematic review of dynamics in climate risk and vulnerability assessments. 12:013002.

Kelman, I., J. Gaillard, and J. Mercer. 2015. Climate Change's Role in Disaster Risk Reduction's Future: Beyond Vulnerability and Resilience. International Journal of Disaster Risk Science 6:21-27.

Liu, W. 2014. The application of resilience assessment - resilience of what, to what, with what? A case study based on Caledon, Ontario, Canada. Ecology and Society 19:21.

Metcalf, S., E. van Putten, S. Frusher, N. Marshall, M. Tull, N. Caputi, M. Haward, A. Hobday, N. Holbrook, S. Jennings, G. Pecl, and J. Shaw. 2015. Measuring the vulnerability of marine social-ecological systems: a prerequisite for the identification of climate change adaptations. Ecology and Society 20:1.

Otto, I., D. Reckien, C. Reyer, R. Marcus, V. Masson, L. Jones, A. Norton, and O. Serdeczny. 2017. Social vulnerability to climate change: a review of concepts and evidence. Regional Environmental Change 17:1651-1662.

Quinlan, A. E., M. Berbés-Blázquez, L. J. Haider, and G. D. Peterson. 2016. Measuring and assessing resilience: broadening understanding through multiple disciplinary perspectives. Journal of Applied Ecology 53:677-687.

Resilience Alliance. 2010. Assessing resilience in social-ecological systems: Workbook for practitioners. Version 2.0. 
Shah, S. H., L. C. Angeles, and L. M. Harris. 2017. Worlding the intangibility of resilience: the case of rice farmers and water-related risk in the Philippines. World Development 98:400-412.

Thiault, L., P. Marshall, S. Gelcich, A. Collin, F. Chlous, and J. Claudet. 2018. Space and time matter in social-ecological vulnerability assessments. Marine Policy 88:213-221.

Weis, S., V. Agostini, L. Roth, B. Gilmer, S. Schill, J. Knowles, and R. Blyther. 2016. Assessing vulnerability: an integrated approach for mapping adaptive capacity, sensitivity, and exposure. Climatic Change 136:615-629.

Wolf, S., J. Hinkel, M. Hallier, A. Bisaro, D. Lincke, C. Ionescu, and R. J. T. Klein. 2013. Clarifying vulnerability definitions and assessments using formalisation. International Journal of Climate Change Strategies and Management 5:54-70. 


\section{Appendix 2}

This appendix presents the detailed protocol used to collect data in the communities. Additionally, it highlights which sections of the protocol informed the different components of the conceptual model.

\section{Protocol for data collection}

\section{Aim of the study}

The aims of the study are to use participatory research methods to identify:

1. Drivers of vulnerability and resilience to climate hazards, perceived by local stakeholders in subsistence farming communities in remote island settings.

2. How current adaptations implemented in those systems are modifying vulnerability and resilience.

\section{Data collection tools to be utilized}

- Gendered focus groups: following culturally appropriate protocols, focus group discussions will be separated by gender to allow participants from both genders to express their opinions openly and freely.

- Transect walks: these will be conducted around the villages, farms and terrestrial and marine environments used by the local communities to support their livelihoods.

- Semi-structured interviews: these interviews will be conducted with key informants in the communities such as the village headmen, village nurses, teachers and community members in leadership roles such as women and youth groups and church groups.

- Participant observation: researchers will immerse themselves in village life and participate in community activities, allowing for researchers to observe how community members manage their resources and interact with natural resources and ecosystems.

Steps for the application of each one of the data collection tools

Prior and informed consent to participate in the research

Before any data collection is carried out, researchers will seek permission from the chief and/or village headman and explain to him/her the nature of our project and how it can benefit the community. This will be done at the moment of the presentation of kava in the community hall. Researchers will ask them if they have any instructions for us to follow or recommendations on how to appropriately approach members of the community for the interviews and organizing focus groups. Permission will also be obtained to record conversations and take photographs.

We will be conducting semi-structured interviews and focus groups with members of the community and households. These focused discussions are aimed to gain insights to reflect on the different elements of the conceptual framework in the following areas:

- Define the boundaries of the system and identify hazards, by providing responses to the questions resilience and vulnerability of what to what? 
- Identify main socio-economic and environmental issues and interaction with ecosystem services provision to link social and ecological vulnerability.

- Use local knowledge and perspectives to identify livelihood strategies that enhance resilience and autonomous adaptation strategies.

For the focused discussions we will have butcher paper with the questions written in English and Fijian. We will write the main ideas in colour cards and use them to keep track of the discussions. At the end of the discussion, we will allow for community members to look at the main ideas collected in the butcher paper and ask them if they think those are the most important points or if we have missed anything. It is important to conclude the focus group by thanking everyone for their time and asking if they have any questions for us.

Highlighted in green we have identified the elements from the conceptual framework that are informed by each section of the data collection.

\section{Questions to guide semi-structured interviews and focus groups}

\section{Section 1: Experienced climate hazards}

1. Considering the past ten years, which have been climate hazards that have impacted the community the most?

Classify them by:

Sudden onset (example storms)

Slow onset (example droughts)

Transient (example weather extremes)

Effectively permanent (example sea level rise)

1.1 How often in the occurrence of this hazard?

1.2 When does this hazard usually occurs?

1.3 How has the hazard most affected your livelihood and the local environment?

1.4 Overall what is the level of impact of that climate hazard to your livelihood, measured as low, medium or high?

Explain the rating system to participants, before asking them to complete the table.

Low = activities or ecosystems were disrupted momentarily but did not sustain damage that required interventions or repair.

Medium=activities or ecosystems were disrupted for a significant amount of time and required interventions to repair or continue.

High $=$ activities or ecosystems were permanently or severely disrupted, and interventions were required to re-build or restore functions. 


\begin{tabular}{|l|l|l|l|l|l|}
\hline $\begin{array}{l}\text { Climate } \\
\text { Hazard }\end{array}$ & $\begin{array}{l}\text { Type of } \\
\text { hazard }\end{array}$ & Frequency & $\begin{array}{l}\text { Season or } \\
\text { time of the } \\
\text { year when it } \\
\text { occurs }\end{array}$ & $\begin{array}{l}\text { Aspects of } \\
\text { livelihoods } \\
\text { and } \\
\text { ecosystems } \\
\text { most } \\
\text { affected by } \\
\text { the hazard }\end{array}$ & $\begin{array}{l}\text { Level of } \\
\text { impact in } \\
\text { livelihoods } \\
\text { (low, } \\
\text { medium, } \\
\text { high) }\end{array}$ \\
\hline Storms & $\begin{array}{l}\text { Sudden } \\
\text { onset }\end{array}$ & Every year & $\begin{array}{l}\text { Rainy season } \\
\text { (between } \\
\text { April and } \\
\text { July) }\end{array}$ & $\begin{array}{l}\text { Roads flood, } \\
\text { stopping } \\
\text { products to } \\
\text { reach } \\
\text { market, } \\
\text { crops die, } \\
\text { animals die, } \\
\text { can't go } \\
\text { fishing) }\end{array}$ & High \\
\hline
\end{tabular}

2. Which climate hazards have posed the biggest challenge for agriculture production and or the environment?

Classify by crop, resource use and type of impact

Link to previous questions about hazards

Post field work: Corroborate and triangulate with records from Bureau of Meteorology and or Ministry of Agriculture

3. Discuss with communities results available on which of the climate hazards are expected to pose a significant higher threat in the future based on available climate change projections. Identify people's perception of this future risk.

This information is used to characterize the hazards, exposure and sensitivity in the conceptual framework.

Section 2: Livelihoods

What are the main sources of livelihood in the community?

Have livelihoods changed in the past recent years? If yes, explain

What are the main assets you count with to support your livelihoods? Classify according to:

- Human Capital

- Social Capital

- Natural Capital

- Physical Capital

- Financial Capital

Information collected in this section is used to characterize adaptive capacity of the system and define the boundaries of the system.

Section 3: Agricultural systems

What types of crops/ animals do you produce?

Which crops/ animals are for household consumption and which ones are for selling? 
What are the main agricultural practices you use in your farm?

What are the biggest production challenges you encounter in your farm?

Who is involved in the production of crops/raising animals?

In the past years have you changed the farming techniques you use, if so, what motivated the change?

In the past years have you changed the crops/animals you produce if so, what motivated the change?

Information collected in this section is used to characterize adaptive capacity of the system and define the boundaries of the system.

Section 4: Fisheries

Which species of fish you get and what are your methods of fishing?

Who is involved in fishing?

Which fishing products are for household consumption and which ones for selling?

Have you had to change fishing techniques and or fishing spots in the past years?

Information collected in this section is used to characterize adaptive capacity of the system and define the boundaries of the system.

Section 5: Ecosystem services

What are the main direct and indirect uses of natural resources in the village for the different livelihoods and stakeholders?

Which drivers or factors appear to influence the provision of ecosystem services? Describe for every type of ecosystem service linked to the livelihoods identified in the community. Classify according to:

- Provisioning services

- Regulating services

- Cultural services

- Supporting services

Information collected in this section is used to characterize linked vulnerability feedbacks between social and ecological sub-systems.

Section 6: Vulnerability drivers

Describe per climate hazard identified in section 1

When a hazard occurs what elements you think are making you more susceptible to the hazard?

Currently what is your capacity to respond to the hazard? In terms of assets, agency and capacity to mobilize those assets.

Information collected in this section is used to characterize vulnerability

Section 7: Resilience drivers

Describe per climate Hazard 
Cope: In the past when a hazard has occurred what has allowed you to recover, even if this meant you were worse than before, but you managed to sustain your household?

Adapt: In the past when a hazard has occurred what has allowed you to adapt and change your management practices to reduce impact from the hazard or to prepare for future hazards?

Transform: In the past when a hazard has occurred what has allowed you to bounce back better and transform your livelihood or what have you done to prepare for the future?

\section{Information collected in this section is used to characterize resilience}

Section 8: Autonomous adaptation strategies

Which strategies have you implemented to prepare or anticipate to a specific hazard?

Which strategies have you implemented to recover from a hazard?

Which strategies you consider would be effective against specific hazards, but you haven't implemented?

What is stopping you from implementing such strategies?

Information collected in this section is used to understand autonomous adaptations and how they have modified vulnerability and resilience

Section 9: Development goals and community aspirations

What goals are a priority for the community to achieve?

What aspects of the community would you like to see improved or maintained?

Information collected in this section is used to understand autonomous adaptations and how they relate to the communities' goals and aspirations. 